\title{
Technical Note: The CCCma third generation AGCM and its extension into the middle atmosphere
}

\author{
J. F. Scinocca, N. A. McFarlane, M. Lazare, J. Li, and D. Plummer \\ Canadian Centre for Climate Modelling and Analysis, Environment Canada, Victoria, B. C., Canada \\ Received: 18 February 2008 - Published in Atmos. Chem. Phys. Discuss.: 21 April 2008 \\ Revised: 13 October 2008 - Accepted: 14 October 2008 - Published: 6 December 2008
}

\begin{abstract}
The Canadian Centre for Climate Modelling and Analysis third generation atmospheric general circulation model (AGCM3) is described. The discussion summarizes the details of the complete physics package emphasizing the changes made relative to the second generation version of the model. AGCM3 is the underlying model for applications which include the IPCC fourth assessment, coupled atmosphere-ocean seasonal forecasting, the first generation of the CCCma earth system model (CanESM1), and middleatmosphere chemistry-climate modelling (CCM). Here we shall focus on issues related to an upwardly extended version of AGCM3, the Canadian Middle-Atmosphere Model (CMAM). The CCM version of CMAM participated in the 2006 WMO/UNEP Scientific Assessment of Ozone Depletion and issues concerning its climate such as the impact of gravity-wave drag, the modelling of a spontaneous QBO, and the seasonality of the breakdown of the Southern Hemisphere polar vortex are discussed here.
\end{abstract}

\section{Introduction}

The development and documentation of an atmospheric general circulation model (AGCM) has become increasingly complicated. The move toward "Earth-system" models has dramatically increased the number and variety of physical processes modelled within the atmosphere as well as their connectivity to other components of the climate system (e.g. the land surface and ocean). On the technical side, the desire for increased resolution as well as the need for multi- centennial ensembles of multiple climate-change scenarios has

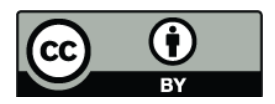

Correspondence to: J. F. Scinocca

(john.scinocca@ec.gc.ca) meant that such models have had to undergo a substantial redesign to make them highly parallelized.

Even at modest spatial resolution, the combined computational expense of model enhancements associated with current AGCM development efforts (e.g. middle-atmosphere modelling, chemical climate modelling, carbon-cycle modelling, clouds and aerosols etc.) greatly outstrip available computational resources. To configure an AGCM suitable for the variety of experiments required for climate change studies one must not only be judicious in the choice of resolution but also in the choice and sophistication of the physical parameterizations included.

One of the final steps in the AGCM development involves a tuning of the model under present-day forcings (e.g. ocean sea-surface temperatures, sea ice characteristics, atmospheric trace constituents etc.). While the term "tuning" has come to have a fairly negative connotation, here we mean simply an adjustment of the "free" parameters associated with each physical parameterization package. Such free parameters, as well as their physical bounds, arise naturally in the derivation of well-posed parameterizations and generally involve the solution of a closure problem. An essential component of this final step is balancing the bottom- and top-of-theatmosphere energy budgets, in preparation for coupling to an ocean GCM. The model configuration that results is then made static (or frozen) ${ }^{1}$.

While the development path outlined above seems complex, it is somewhat idealized. In reality, AGCMs typically undergo a process of continual development which only accelerates with the number and variety of its applications. This is because each application provides valuable information about the properties of the model which serves to

\footnotetext{
${ }^{1}$ Further tuning may also occur for the coupled atmosphereocean configuration of the GCM.
} 
improve its formulation and focus future model development efforts. The desire to include model improvements as they arise means that a definitive description or documentation of the AGCM used for any particular project is often difficult to obtain.

The focus of this paper is the Canadian Centre for Climate Modelling and Analysis (CCCma) third-generation atmospheric climate model AGCM3 (McFarlane et al., 2005). AGCM3 is not a "new" model. It was first made static more than five years ago. Since this time AGCM3 has been used for a variety of applications addressing issues related to climate change (Intergovernmental Panel on Climate Change Fourth Assessment), middle-atmosphere and chemical climate modelling (WMO/UNEP, 2007; Eyring et al., 2006, 2007), seasonal forecasting, and its output and a number of its physical parameterizations are used in the Canadian Regional Climate model (Plummer et al., 2006).

The purpose of this paper is twofold. First, it serves to document the properties of AGCM3 and its associated physical parameterizations. The second purpose of this paper is to document the formulation of AGCM3 used for middle atmosphere and chemical climate modelling studies (e.g. WMO/UNEP 2007; Eyring et al., 2006, 2007). It is in this configuration that AGCM3 will continue to be used for a number of upcoming chemical climate applications. The upward extension of AGCM3 is often referred to as the Canadian Middle Atmosphere Model (CMAM). Here we will focus on the "dynamical" version of CMAM (i.e. no chemistry), which we will refer to as DYN-MAM. The goal will be to document the configuration of AGCM3 that defines CMAM and several of the sensitivities that are important to its CCM configuration.

The outline of the paper is as follows. In Sect. 2 we will document the basic properties of static AGCM3 with particular attention to the physical parameterizations. In Sect. 3 we discuss the configuration of AGCM3 that supports its use as a middle-atmosphere model suitable for climate studies. In Sect. 4, we present some properties and sensitivities of the DYN-MAM climate that are important for its use as a base for CCM modelling. Finally, in Sect. 5 we conclude with a brief summary.

\section{AGCM3 tropospheric configuration}

In this section we document a number of the properties of static AGCM3 which heretofore have not been available in the literature. A more detailed technical summary may be found in the report by McFarlane et. al. (2005, hereafter referred to as M05). Where possible, the properties of AGCM3 will be related to those of its predecessor, AGCM2 (McFarlane et al., 1992). A detailed discussion and documentation of the AGCM3 control climate can be found in M05 and references therein.

\subsection{Model numerics}

Following AGCM2, AGCM3 employs a spectral dynamical core with a hybrid sigma-pressure coordinate in the vertical which is discretized by rectangular finite elements (Laprise and Girard, 1990). Slight differences in the definition of pressure on these coordinate surfaces exists between AGCM2 and AGCM3. These are described in M05. Standard horizontal resolutions of AGCM3 are defined by triangular truncation at total wavenumbers of $\mathrm{M}=47$ (T47) and $\mathrm{M}=63$ (T63). Typically, 31 vertical levels are employed with layer thicknesses that increase monotonically from approximately $100 \mathrm{~m}$ at the surface to approximately $3 \mathrm{~km}$ at $1 \mathrm{hPa}$.

Nonlinear advection terms are evaluated in physical space on a Gaussian grid of sufficient size (i.e. $(3 M+1) / 2$ latitudes) to prevent the aliasing of quadratic nonlinearities (e.g. Orszag, 1970). This grid is often referred to as the "nonlinear" or "quadratic" grid. The usual practise is to evaluate physical tendencies (e.g. radiation, deep convection) on the quadratic grid (i.e. "single transform" method). This was employed previously by AGCM2. In AGCM3 a second spectral transform is introduced to allow the evaluation of physical tendencies on a smaller Gaussian grid. This "double transform" approach uses the "linear" Gaussian grid which contains $(2 \mathrm{M}+1) / 2$ latitudes. Employing the double transform allows the physical tendencies to be applied as a correction step to the advection in the time-stepping algorithm.

The linear grid is the smallest Gaussian grid that allows an exact (to machine precision) spectral transform to and from physical space. Relative to the quadratic grid, the linear grid has more than a factor of 2 reduction in the total number of grid points. Since the calculation of physical tendencies represents the largest cost of the AGCM, a significant saving is realized by employing the double transform approach.

The issue of single vs double transforms has been the source of some confusion in characterizing the spatial resolution of spectral models. For example, the precipitation fields from the T31 operational version of AGCM2 and those from the T47 version of AGCM3 appear on the same $96 \times 48$ Gaussian grid (representing the quadratic grid for AGCM2 and the linear grid for AGCM3). The precipitation field associated with the T47 model, however, contains more spatial information because it was derived from input fields of temperature and specific humidity of higher spatial resolution. Further, whichever grid is employed, the physical tendencies derived are truncated back to the spectral resolution employed before updating the prognostic fields. Therefore, the true resolution of the model is specified by the spectral truncation, not by the grid employed to evaluate physical tendencies.

The spectral representation of topography in AGCM3 has been modified relative to the simple spectral truncation used for AGCM2. Spectral truncation results in significant Gibbs oscillations at locations where sharp gradients occur (e.g. the Andes and Himalayas). Such oscillations lead to artifacts in the application of sub-grid-scale parameterizations which 
must be evaluated on the physical grid. To mitigate these effects a procedure has been developed (Holzer, 1996) to produce an "optimal" spectral representation of the topography that substantially reduces Gibbs oscillations. This procedure smooths the topography employing a cost function that depends on both the height of the topography and its gradients.

\subsection{Tracer advection and hybridization}

In AGCM3 an option to advect moisture and other prognostic tracer quantities using a semi-Lagrangian treatment has been included. The scheme employs a cubic spline interpolation to obtain the concentration at the upstream departure point and includes corrections for monotonicity and mass conservation (Priestley, 1993). After extensive experimentation it was found that Semi-Lagrangian advection led to excessive numerical diffusion of the tracers. This is due to the fact that the CFL constraint on the time step of the spectral dynamical core requires Courant numbers less than 1 while the semi-Lagrangian scheme is most accurate for Courant numbers exceeding 1 .

Following the procedure first discussed by Boer (1995) and more recently by Merryfield et al. (2003), a "hybrid" moisture variable is used in AGCM3 to mitigate artifacts such as negative values of specific humidity associated with spectral advection. As described in Merryfield et al. (2003), important benefits of the hybrid procedure include shape preservation irrespective of the advection algorithm employed. This approach has now been generalized and made available for application to any tracer field and it is useful to review the methodology.

In the hybridization procedure a transformed version of a variable, say specific humidity $q$, is employed for the purpose of advection in the GCM. A general form of the transformation employed in AGCM3 may be motivated as follows: consider the identity:

$q \equiv \frac{q_{o}}{\left[\exp \left(p \ln \left(q_{o} / q\right)\right)\right]^{1 / p}}$,

where $q_{o}$ and $p$ are constants. Performing a Taylor series expansion of the denominator and retaining terms to first order in $q_{o} / q$ results in the expression for the right-hand side of Eq. (1):

$$
\frac{q_{o}}{\left[1+p \ln \left(\frac{q_{o}}{q}\right)\right]^{1 / p}}
$$

The expression Eq. (2) is the transformation upon which the hybrid procedure is based in AGCM3. Specifically, the hybrid transform is defined as:

$s= \begin{cases}q, & q>q_{o} \\ \frac{q_{o}}{\left[1+p \ln \left(\frac{q_{o}}{q}\right)\right]^{1 / p}}, & q \leq q_{o},\end{cases}$

or equivalently

$q=s H(\alpha)+(1-H(\alpha)) q_{o} \exp \left[\frac{1-\left(q_{o} / s\right)^{p}}{p}\right]$, where $H(\alpha)$ is the Heaviside function and $\alpha=s / q_{o}-1$.

In GCM3 a value of $p=1$ is employed. As noted by Boer (1995) the use of $q_{o}$ typical of the mean tropospheric specific humidity substantially alleviates the tendency to develop negative values associated with spectral advection. Hence it alleviates most of the undesirable effects that accompany the ad hoc conservative hole filling procedures that were used in AGCM2 with specific humidity being advected spectrally.

One of the more useful properties of spectral models is their ability to perform advection in a conservative manner. In general, use of the hybrid variable $s$ in place of $q$ for spectral advection means that $q$ is no longer identically conserved. Much of this conservation can be recovered by "fine tuning" the value of $q_{o}$. Exact conservation is enforced on any remaining imbalance following the procedure outlined below.

Just after advection, given $s$ and the constant $q_{o}$, one can determine $q$ on the physics grid from Eq. (4). The total mass $M$ of $q$ is given by the volume integral

$M=\iiint \rho q d V$.

For exact conservation, this must be equal to $M_{o}$ - the total mass just prior to the advection step. Exact conservation is enforced by adjusting the $q$ field smoothly over the range $q_{\text {low }} \leq q \leq q_{o}$ after each advective time step. The new $q$ field that employs this correction is written

$q_{\text {new }}= \begin{cases}q+C\left(q-q_{\text {low }}\right)\left(q_{o}-q\right), & q_{\text {low }} \leq q \leq q_{o} \\ q, & \text { otherwise. }\end{cases}$

Globally integrating Eq. (6) and equating this to $M_{o}$ defines the necessary value of $C$ to enforce conservation:

$C=\frac{M_{o}-M}{\iiint \rho\left(q-q_{\text {low }}\right)\left(q_{o}-q\right) d V}$.

In AGCM3 hybridization is applied to specific humidity and standard spectral advection is employed for all remaining prognostic fields. In the hybridization of specific humidity, reference values of $q_{o}=0.01 \mathrm{~kg} / \mathrm{kg}, p=1$, and $q_{\text {low }}=q_{o} / 10$ are used for the default configuration. A simple example highlighting the utility of the hybrid procedure is provided in the Appendix.

\subsection{Land surface scheme}

AGCM3 employs a more sophisticated treatment of energy and moisture fluxes at the land surface compared to AGCM2. These quantities are now calculated within the Canadian Land Surface Scheme (CLASS) module. CLASS was first introduced in the late 1980s and has subsequently undergone a number of modifications (Verseghy, 1991, 1993, 2000). The version of CLASS currently used in the GCM is referred to as version 2.7. A brief outline of its structure is provided below. 
CLASS allows up to four subareas for each land-surface grid cell: bare soil, vegetation-covered soil, snow-covered soil, and soil covered by both vegetation and snow. At each time step the following fields are supplied as input from the AGCM to CLASS: incoming short-wave and long-wave radiation, the ambient air temperature and humidity, the wind speed, and the precipitation rate. Energy and moisture budgets for each subarea are calculated independently and surface fluxes are averaged over the grid cell prior to output to the AGCM. As described in the next subsection, turbulent fluxes at the land surface are evaluated following Abdella and McFarlane (1996).

The soil profile is divided into three horizontal layers, of thicknesses $0.10,0.25$ and $3.75 \mathrm{~m}$. The texture of each layer, and the overall depth to bedrock, are derived from the global data set assembled by Webb et al. (1993). The hydraulic properties of the soil layers are obtained from the soil texture using relationships developed by Cosby et al. (1984). The layer temperatures and liquid and frozen moisture contents are carried as prognostic variables, and are stepped forward in time using the fluxes calculated at the top and bottom of each layer. Energy fluxes are obtained from the solution of the surface energy balance, expressed as a function of the surface temperature and solved by iteration. The soil albedo and thermal properties vary with texture and moisture content. Moisture fluxes are determined using classic Darcy theory in the case of drainage and capillary rise, and after the method of Mein and Larson (1973) in the case of infiltration. If the surface infiltration capacity is exceeded, water is allowed to pond on the surface up to a maximum depth which varies by land cover. Continental ice sheets are modelled in the same way as bare soil, using the thermal properties of ice instead of soil minerals.

Snow is modelled as a fourth, variable-depth soil layer with its own prognostic temperature. Density and albedo vary exponentially with time, from fresh-snow values to specified background values, according to relationships derived from field data. Melting occurs if either the surface temperature or the snow pack layer temperature is projected to rise above $0^{\circ} \mathrm{C}$. In this case, the excess energy is used to melt part of the snow pack and the temperature is set back to $0^{\circ} \mathrm{C}$. Meltwater percolates into the pack and refreezes until the whole layer reaches $0^{\circ} \mathrm{C}$, at which point any further melt is allowed to reach the soil surface. Snowmelt decreases the thickness of the pack until a limiting depth of $0.10 \mathrm{~m}$ is reached; after this, the snow pack is assumed to become discontinuous, and a fractional snow cover is calculated by setting the depth back to $0.10 \mathrm{~m}$ and employing conservation of mass.

Vegetation types present over each grid cell are obtained from the global data set compiled by Wilson and HendersonSellers (1985). Vegetation height, maximum and minimum leaf area index, visible and near-IR albedos, canopy mass, and rooting depth are specified for each vegetation type following Verseghy (1991). Derived properties such as the short-wave radiation extinction coefficient, the canopy gap fraction, the roughness lengths for heat and momentum, and the annual cycle of leaf area index are determined separately for coniferous trees, deciduous trees, crops, and grass, and are then averaged over the grid cell to define the bulk canopy characteristics. The canopy temperature, and the liquid and frozen intercepted water, are carried as prognostic variables. The interception capacity is calculated as a function of leaf area index. Stomatal resistance to transpiration is parameterized as a function of incoming short-wave radiation, air vapour pressure deficit, canopy temperature and soil moisture, using functional relationships similar to those presented by Stewart (1988).

\subsection{Surface-flux formulation}

The surface flux formulation used in AGCM3 is as described by Abdella and McFarlane (1996). This formulation is based on the Monin and Obukhov (1954) theory and employs the flux profile relations of Beljaars and Holtslag (1991). An efficient procedure for evaluating the surface fluxes as functions of stability is derived by representing the ratio of the depth of the surface layer to the Monin-Obukhov length, a fundamental quantity in Monin-Obukhov theory, in terms of the bulk Richardson number for the surface layer. Further details may be found in Abdella and McFarlane (1996) and M05.

\subsection{Turbulent transfer in the free atmosphere}

The turbulent transfer of scalar quantities in the boundary layer involve both local down-gradient transfer processes and non-local counter-gradient transfer processes. In a convectively active cloud-free boundary layer non-local transfers bring about and maintain a well mixed state in which quasi-conserved scalar variables are vertically homogeneous through most of the boundary layer.

In AGCM3 the treatment of non-local PBL processes on any scalar $\chi$ is based on the assumption that such processes are well modelled by a temporal relaxation toward a vertically homogeneous reference state $\chi_{R}$. This formulation applies to potential temperature, specific humidity, and any advected scalar tracer fields included in the model. The reference state is derived by assuming that the vertical flux of $\chi$ vanishes at the top of the mixing region. The top of the mixing region is defined as the lowest level where the ambient and reference values of virtual potential temperature are equal. Further details may be found in M05. It is important to point out that the present approach does not account for clouds in the convectively active PBL. In the CCCma fourth generation AGCM this approach is extended to cloudy situations by combination with a statistical cloud scheme.

The local down-gradient turbulent transfer of momentum, heat, and any additional tracers is accounted for in terms of diffusivities which depend on the vertical wind shear and the local gradient Richardson number. This is similar to the 
formulation used for AGCM2. Diffusivities have large values within the PBL and decrease rapidly above to specified background values. AGCM3 uses background diffusivities of $0.01 \mathrm{~m}^{2} \mathrm{~s}^{-1}$ for momentum and $0.001 \mathrm{~m}^{2} \mathrm{~s}^{-1}$ for all other prognostic variables. Further details may be found in M05.

\subsection{Orographic drag}

AGCM3 uses the Scinocca and McFarlane (2000; hereafter SM) scheme for the parameterization of drag associated with unresolved mesoscale orography. In addition to gravity-wave drag (GWD) associated with freely propagating waves, the SM scheme parameterizes drag for dynamics associated with low-level "blocking". This replaces the McFarlane (1987) scheme which treated only GWD. Relative to McFarlane (1987), SM demonstrate that this new scheme provides a quantitative reduction in the wind and mean-sealevel pressure biases in AGCM3.

For the parameterization of drag associated with freely propagating waves the SM scheme is designed to include anisotropic effects. For example, the total amount of momentum transported vertically by the waves depends on the wind direction relative to the orientation of the unresolved topography in each AGCM grid cell. This is accomplished by characterizing the sub-grid topography by a variable number of identical ellipses and using the linear theory derived by Phillips (1984) to determine pressure drag associated with the 3-D wave field.

The azimuthal distribution of momentum within the wave field is also modelled by the SM scheme. This is accomplished by employing two sinusoidal waves to transport the total momentum vertically. The two waves represent the net momentum directed to the left and right of the current wind direction. In this way the magnitude and orientation of the waves' momentum flux continuously vary producing a realistic representation of anisotropy in the parameterized wave field.

The deposition of momentum from the waves to the mean flow closely follows McFarlane (1987). Based on stability arguments, the nondimensional amplitude of each wave $F r=\mathrm{N} A / \mathrm{U}$ is restricted to a maximum value of $F r_{\text {crit }}$, where $A$ is the peak vertical displacement amplitude of the wave, and $\mathrm{U}$ and $\mathrm{N}$ are the grid mean values of wind and buoyancy frequency respectively. Following McFarlane (1987) a value of $F r_{\text {crit }}=\sqrt{(0.5)}$ is used in AGCM3. If a local measure of the wave amplitude exceeds $F r_{\text {crit }}$ then momentum is transferred from the wave to the mean flow. SM also include a parameterization of downslope windstorm effects which significantly enhance the drag in the troposphere.

The parameterization of low-level drag activates when the nondimensional height of the subgrid topography $(N h / U)$ exceeds $F r_{\text {crit }}$, where $h$ is the peak height of the subgridscale obsticle. In this instance empirical evidence (Ölaffson and Bougault, 1996) indicates that the flow is blocked to a depth $N h / U-F r_{\text {crit }}$. In the SM scheme form drag associated with bluff-body dynamics is employed to model this blocking effect. Anisotropy is introduced into the formulation by diagnosing 2-D ridge-like structure in the unresolved topography in each grid cell. The depth of the blocking layer depends on whether the flow is oriented along (shallow), or normal to (deep), ridge-like structure. Therefore, in addition to retarding the flow, the SM blocking formulation causes a redirection of the low-level flow so that it is more aligned with ridge-like structure in the unresolved topography.

\subsection{Moist convection}

In AGCM3 the penetrative mass flux scheme of Zhang and McFarlane (1995; hereafter ZM) is used to model the precipitation and latent heat release associated with deep cumulus convection. This replaces the moist convective adjustment scheme (Daley et al., 1976) employed previously in AGCM2.

The ZM scheme is based on a bulk representation for an ensemble of cumulus clouds comprised of entraining updrafts and evaporatively driven downdrafts. The novelty of the ZM parameterization arises from several key simplifying assumptions. One of the most important of these is that all sub-ensembles have the same initial cloud-base updraft mass flux. The ZM approach results in an economical scheme that efficiently captures the salient features of the more general problem (Arakawa and Schubert 1974, Lord et al., 1982; Moorthi and Suarez, 1992).

Another simplifying assumption of the $\mathrm{ZM}$ scheme is that all ensembles of evaporatively driven downdrafts initiate with the same downdraft mass flux. An important constraint is that the net mass flux at cloud base (updraft plus downdraft) be non-negative. The manner in which this condition is satisfied in AGCM3 is described in Appendix C of Scinocca and McFarlane (2004). As discussed in Scinocca and McFarlane (2004), the "weight" parameter $\mu$, which helps determine the amount of rainwater evaporated into the downdrafts, turns out to be an important tuning parameter for the mean climate and the variability of tropical precipitation. In AGCM3 a standard value of $\mu=1$ is used.

The assumption that all sub-ensembles have identical cloud-base mass flux, allows the ZM scheme to derive its closure based on an individual member of the ensemble. The closure uses a notional budget equation for convective available potential energy (CAPE). This may be written symbolically as:

$$
\frac{\partial A}{\partial t}=-M_{b} F+G
$$

where $A$ represents CAPE, $G$ represents the large-scale production of CAPE by resolved dynamics, and $-M_{b} F$ represents the sub-grid depletion of CAPE by parameterized deep convection. Following ZM, $M_{b}$ represents the cloud-base updraft mass flux, while $F$ represents the rate at which cumulus clouds consume CAPE per unit cloud-base updraft mass flux. The quantity $F$ is central to the parameterization problem. 
At any time its value will depend upon the current profiles of temperature and specific humidity as well as the assumed properties of typical of updrafts and downdrafts in deep convective towers (see ZM and M05).

$\mathrm{ZM}$ employ the diagnostic closure condition:

$M_{b}=\frac{A}{\tau_{a} F}$,

where $\tau_{a}$ is an adjustment time scale. Physically, this closure assumes that CAPE is consumed at an exponential rate $\left(1 / \tau_{a}\right)$ by cumulus convection. A value of $\tau_{a}=2400 \mathrm{~s}$ is used and there is no triggering mechanism implemented - at all times positive CAPE results in the onset of deep convection. Modification of the ZM scheme to include a prognostic closure has been discussed by Scinocca and McFarlane (2004).

\subsection{Radiation}

The basic treatment of radiation in AGCM3 is similar to GCM2 in that solar radiation is treated following Fouquart and Bonnel (1980) and terrestrial radiation following Morcrette (1989). However a number of improvements have been introduced in AGCM3. The clear sky infrared radiation is similar to that in GCM2 with 6 bands covering a spectral range from 0 to $3000 \mathrm{~cm}^{-1}$, but with more complicated sub-band structure in order to obtain more accurate gaseous transmission. The band spectral ranges are $1.0-350 \mathrm{~cm}^{-1}$ and $1450-1880 \mathrm{~cm}^{-1}$, 2. $500-800 \mathrm{~cm}^{-1}, 3.800-970 \mathrm{~cm}^{-1}$, and $1110-1250 \mathrm{~cm}^{-1}, 4.970-1110 \mathrm{~cm}^{-1}, 5.350-500 \mathrm{~cm}^{-1}$, 6. $1250-1450 \mathrm{~cm}^{-1}$ and $1880-2820 \mathrm{~cm}^{-1}$. Water vapour, $\mathrm{CO}_{2}, \mathrm{CH}_{4}, \mathrm{~N}_{2} \mathrm{O}, \mathrm{O}_{3}, \mathrm{CFC}-11$, and $\mathrm{CFC}-12$ are considered in gaseous transmission.

The most significant change involves the treatment of the water vapour continuum. In GCM2, the Roberts (1976) parameterization for water vapour continuum was used. In AGCM3 this has been replaced by the newer scheme of Zhong and Haigh (1995), which is based on version 2.2 of Clough et al. (1989), often referred to as CDK2.2. Unlike the Roberts parameterization, which is mostly restricted in the window region, in the parameterization of Zhong and Haigh the water vapour continuum contributes throughout the complete infrared bands for both the self-broadened part and foreign self-broadened part. Zhong and Haigh (1995) clearly show that their parameterization has considerable influence on the infrared cooling rate. After implementing the new water vapour continuum parameterization, it was found that the lower tropospheric cooling rate was typically reduced by about $0.5 \mathrm{~K} /$ day in the tropics, which is consistent with the calculation results of Zhong and Haigh (1995).

The transmission data for other trace gases has been updated with a parameterization based on Padé approximation (e.g. Baker, 1975). It is found that the important contribution of $\mathrm{N}_{2} \mathrm{O}$ in band 3 was absent in AGCM2. This could cause a few $\mathrm{Wm}^{-2}$ increase in upward flux at the top of the atmosphere and larger cooling in the lower troposphere. For all gases presented, the difference in upward flux at the top of the atmosphere between the AGCM2 and AGCM3 could be several $\mathrm{Wm}^{-2}$. A comparison of AGCM3 infrared radiation with line-by-line calculations and observations is shown in Evans et al. (2004).

For the treatment of solar radiation in AGCM3, a four band spectral transmission scheme is used for solar radiation rather than the two-band scheme used in AGCM2. The band structures are: 1 . $0.25-0.69 \mu \mathrm{m}, 2$. $0.69-1.19 \mu \mathrm{m}, 3$. $1.19-2.38 \mu \mathrm{m}$ and 4. $2.38-4.0 \mu \mathrm{m}$. $\mathrm{O}_{3}$, water vapour, $\mathrm{CO}_{2}$, and $\mathrm{O}_{2}$ are considered for gaseous transmission. All gaseous transmission data are updated with 6 term Padé approximation. Typically, the solar portion of the radiation is calculated every hour while the infrared portion is calculated every six hours.

It is found that for clear sky radiation the difference between the previous two-band scheme and the present fourband scheme is small. However the extension to a four-band scheme permits a more accurate treatment of cloud-radiation and aerosol-radiation interactions. Since the solar energy distribution is highly inhomogeneous, the two-band scheme could not resolve the solar energy distribution adequately and this leads to an overestimation of the cloud induced solar heating rate. In AGCM2, constant values for single scattering albedo and asymmetry factor are used for both liquid water cloud and ice water cloud. In AGCM3, the updated multi-band structure enable using the four band Slingo parameterization (Slingo, 1989) for liquid water optical properties (details below).

\subsection{Clouds}

In both AGCM2 and AGCM3 the cloud cover $C$ is determined diagnostically based on a relative humidity excess, $R$, defined as:

$R=\frac{\operatorname{Max}\left(H-H_{o}, 0\right)}{1-H_{o}}$,

where $H$ is relative humidity and $H_{o}$ is a "threshold" value of $H$. In AGCM2, the cloud cover was taken to depend linearly on $R$ (i.e. $C=R$ ) and $H_{O}$ was a specified function of height (local sigma value).

In AGCM3 the cloud cover is made to vary smoothly between a linear and quadratic dependence on $R$ based on a conditional stability parameter determined by the gradient of potential temperature relative to its value on a local moist adiabat:

$\tilde{C}=R \frac{(R+\Lambda)}{(1+\Lambda)}$.

In Eq. (11) $\Lambda$ is the conditional stability parameter

$\Lambda=\left[\frac{\operatorname{Max}\left(\Gamma-\Gamma_{s}, 0\right)}{\Gamma_{s}}\right]^{2}$,

where $\Gamma$ is the gradient of potential temperature and $\Gamma_{s}$ is the value of $\Gamma$ in a local moist adiabat. From Eq. (11) it can 
be seen that the quantity $\tilde{C}$ varies smoothly between a linear dependence for conditionally stable conditions $(\Lambda>>1)$ to a quadratic dependence for conditionally unstable conditions $(\Lambda=0)$. With $C=\tilde{C}$ the dependence on $\Lambda$ replaces the more artificial height dependence of $H_{o}$ in AGCM2.

In AGCM3 the threshold relative humidity $H_{o}$ is no longer taken to be a function of height. For ice clouds values of $H_{o}^{i}=0.825$ and $H_{o}^{i}=0.75$ are respectively used for resolutions of T47 and T63. Also, for ice clouds, the cloud path is scaled down by an expansion factor $C=F \tilde{C}$, where

$F=\frac{(1+\Lambda)}{(1+\tilde{C} \Lambda)}$

This results in a weaker dependence of $C$ on $H$ in stably stratified conditions.

For water clouds, AGCM3 uses $C=\tilde{C}$. Empirical tuning simulations with AGCM3 revealed improvement if the threshold relative humidity, $H_{o}^{w}$, was made to be a weak function of the conditional stability factor $\Lambda$. The form used is

$$
H_{o}^{w}=\frac{H_{o}^{w_{1}}+H_{o}^{w_{2}} \Lambda}{1+\Lambda}
$$

where $H_{o}^{w_{1}} \geq H_{o}^{w_{2}}$. In AGCM3 $\left(H_{o}^{w_{1}}, H_{o}^{w_{2}}\right)$ is $(0.95,0.89)$ and $(0.95,0.87)$ respectively for T47 and T63.

Cloud optical properties required for the radiative transfer calculations are based on the diagnostic formulation used in AGCM2. In this approach, the cloud liquid water content is assumed to be proportional to the adiabatic water content of an air parcel lifted through a small vertical displacement. The specific details of this approach may be found in M05.

\subsection{Aerosol}

A background distribution of aerosol loading is specified in AGCM3 for the purpose of radiative transfer calculations. The distributions of aerosols are distinguished as continental and maritime. For continental, the specified aerosol types are dust-like, water-soluble (mostly), and soot. The column amount is $57.71 \mathrm{mg} \mathrm{m}^{-2}$ for dust-like aerosol, $2.55 \mathrm{mg} \mathrm{m}^{-2}$ for water-soluble aerosol, and $0.2 \mathrm{mg} \mathrm{m}^{-2}$ for soot aerosol. For maritime, the specified aerosols are oceanic (mostly sea salt) and water-soluble. The loading is $18.82 \mathrm{mg} \mathrm{m}^{-2}$ for oceanic and $0.263 \mathrm{mg} \mathrm{m}^{-2}$ for watersoluble. The aerosol optical properties are calculated based on Shettle and Fenn (1979). All background aerosols are assumed to be homogeneously distribution within the boundary layer.

\section{AGCM3 middle-atmosphere configuration}

In this section we discuss the extension of AGCM3 into the middle atmosphere. This is commonly referred to as the Canadian Middle-Atmosphere Model (CMAM). The discussion will focus on the "dynamical" CMAM, or DYN-MAM (i.e. the upward extension of AGCM3 in the absence of chemistry). The earliest configuration of DYN-MAM was discussed by Beagley et al. (1997). Various incremental versions of DYN-MAM have been employed to investigate a variety of applications including non-orographic gravity-wave drag parameterization (e.g. Medvedev and Klaassen, 1995; McLandress, 1997; Manzini and McFarlane, 1998; Scinocca, 2002, 2003; Mclandress and Scinocca, 2005), diurnal tides (e.g. McLandress and Ward, 1995; McLandress, 1997; Jonsson et al., 2002), and stratospheric mixing regimes (Koshyk et al., 1999).

DYN-MAM also serves as a base model for chemistry climate modelling. Various incremental versions of the chemistry-climate version of CMAM, referred to here as CCM-MAM, have been employed for deriving ozone climatologies (deGrandpré et al., 2000), data assimilation (Polavarapu et al., 2005), and investigating climate-change issues related to ozone (Austin et al., 2003). The version of CMAM documented here pertains to the most recent applications of CCM-MAM for climate change studies as part of the CCMVal project and 2006 WMO Ozone Assessment (WMO/UNEP, 2007; Eyring et al., 2006, 2007; de Grandprié et al., 2000). This version of CCM-MAM will also be used for fully coupled atmosphere-ocean climate change studies as part of the Canadian SPARC initiative.

The primary purpose of this section is to discuss the particular configuration of DYN-MAM which forms the base model for current and future chemical climate modelling efforts. An important goal of this effort is to obtain a climatology of winds and temperatures that is suitable for this work. For example, sufficiently cold temperatures at the winter poles in the lower stratosphere are required to allow the formation of polar stratosphere clouds (PSCs) which allow the heterogeneous chemical reactions that drive polar ozone loss.

Another important issue involves the timing of the breakdown of the wintertime southern-hemisphere stratospheric polar vortex. As shown in Eyring et al. (2006), relative to UKMO reanalysis data, most CCMs display a systematic bias in which the breakdown of the SH polar vortex is delayed by as much as one month in some models. In CCM-MAM this breakdown is delayed by approximately two weeks. Here we shall consider the origins of this bias in the DYN-MAM. Finally, we consider the ability of CMAM to support a spontaneous quasi-biennial oscillation (QBO). 


\subsection{DYN-MAM Physics}

As the lid of the model is raised into the stratosphere and mesosphere, assumptions regarding local thermodynamic equilibrium (LTE) begin to break down and the accuracy of the infrared (IR) component of the radiation scheme described in Sect. 2.8 rapidly degrades. The approach initially followed in CMAM was to employ a more accurate IR scheme (Fomichev et al., 1993; Fomichev and Blanchet, 1995) in the stratosphere and mesosphere with a region of transition between the two schemes occurring over the range $40-7 \mathrm{hPa}$. More recently, additional improvements to the radiation above this transition region include a new $15 \mu \mathrm{m} \mathrm{CO}_{2}$ parameterization (Fomichev et al., 1998), near-infrared $\mathrm{CO}_{2}$ solar heating with non-LTE effects included (Ogibalov and Fomichev, 2003; Fomichev et al., 2004), water vapor IR cooling, non-unit efficiency for solar $\mathrm{O}_{3}$ heating in the mesosphere, solar $\mathrm{O}_{2}$ heating in the Schumann-Runge bands and continuum, the effect of sphericity, and chemical heating (in the CCM-MAM version). The details of these improvements are outlined in Fomichev et al. (2004).

The role of gravity-wave drag (GWD) in the middle atmosphere is now well appreciated. Such waves generally originate in the troposphere, where the winds are predominantly Westerly, and propagate vertically into the middle atmosphere. As they propagate vertically these waves amplify due to the decrease in ambient density ultimately leading to instability in the wave field. Such instability results in the breakdown and dissipation of the waves producing a torque on the flow which always acts to "drag" the winds towards the phase speed of the dissipating waves.

In mid-latitude summer conditions, upwardly propagating waves move from a basic state comprised of Westerlies in the troposphere to one of Easterlies in the stratosphere. Consequently, zero phase speed waves (e.g. orographic waves) are generally filtered from the stratosphere by critical layer interactions near the elevation where the zonal winds vanish. The requirement of GWD further aloft (e.g. to induce the summertime mesopause wind reversal) necessitates the parameterization of gravity waves with non-zero horizontal phase speeds often referred to as non-orographic waves. The tropospheric sources of non-ororgraphic gravity waves are dynamical in nature and many are the subject of physical parameterizations themselves (e.g. deep cumulus convection).

The CMAM model has been at the forefront of nonorographic gravity-wave drag parameterization. In its earliest development CMAM optionally employed the schemes of Hines (1997) and Medvedev and Klaassen (1995). More recently the CMAM has employed the scheme of Scinocca (2003) which is an exact hydrostatic, non-rotating, version of the Warner and McIntyre (1996) parameterization. CMAM wind and temperature climatologies resulting from the use of the Scinocca (2003) scheme as well as comparisons with Hines (1997) and the full non-hydrostatic form of the scheme (Scinocca, 2002) may be found in Scinocca (2003). Both orographic and non-orographic gravity-wave drag have an important impact on the climatological winds and temperatures of the middle atmosphere and this will be discussed in more detail in the next section.

Finally, the use of CMAM as a base for chemical climate modelling means that the spectral treatment of tracer advection is a potential concern. While AGCM3 supports an optional Semi-Lagrangian advection scheme for tracers, this was found to be too diffusive for the reasons outlined in Sect. 2.2. The strategy adopted here is to employ standard spectral advection for all chemical tracers and attempt to mitigate the associated artifacts, which are describe below.

Spectral advection has increasingly fallen from favour as an algorithm for tracer advection. However, it is important to recognize that when the flow and tracer fields are adequately resolved, spectral advection conserves the mean of the tracer and provides an accurate representation of all higher-order moments of its distribution. The problems arise when power develops at the truncation scale of the model causing the flow and tracer fields to become poorly resolved. In this instance, spectral advection produces significant Gibbs oscillations which lead to localized pockets of negative tracer concentration requiring ad hoc hole-filling algorithms to preserve monotonicity. One approach to deal with this problem is the application of hybrid tracers described in Sect. 2.2. While the hybrid approach can significantly reduce Gibbs oscillations and provide improved shape preservation of the tracer field, transform parameters for each tracer are unique and must be determined iteratively. Due to the many tracers required by the chemistry package the hybridization approach becomes less appealing.

For the purpose of chemical climate modelling we have adopted a more straightforward approach in which basic spectral advection is employed for tracers and effort is invested to ensure that adequate resolution of the flow and tracer fields is maintained throughout the simulation. To achieve this goal one must address the basic question of how, for a given horizontal diffusion and spatial resolution, the flow obtains power at the truncation scale causing it to become under resolved. One might imagine that such power is produced by resolved dynamical motions such as the downscale cascade associated with chaotic advection of the tracer field. However, if this were the case then it would simply point to the fact that the resolution was insufficient for the given strength of horizontal diffusion employed or, conversely, that the strength of horizontal diffusion was insufficient for the given horizontal resolution.

In fact, the dominant source of power at the truncation scale of the GCM is the physics package whose tendencies force these scales directly. Because of threshold physical processes, these tendencies can be spatially discontinuous resulting in the direct production of structure at the truncation scale of the model. For a GCM employing a spectral dynamical core, such structure is rapidly converted into Gibbs 
oscillations which, in addition to producing spurious physical tendencies, can themselves induce a positive feedback cycle perpetuating the Gibbs oscillations.

The approach taken here is to mitigate the impact of Gibbs oscillations and the tendency of threshold physical processes to produce truncation scale structure. This is achieved by employing what we will refer to as a "physics filter" following the work of Landers and Hoskins (1997, hereafter LH97). From a series of idealized examples LH97 argued that such problems could be greatly alleviated by first spatially filtering the copies of the prognostic fields used as input to the physics package. In this way Gibbs oscillations, and any associated spurious physical tendencies, would be suppressed. Secondly, LH97 argued that the tendencies produced by the physics package should also be spatially filtered prior to updating the prognostic fields of the model. This would smooth out any discontinuities produced by threshold processes in the physics. Collectively, these two filtering processes are referred to as the "physics filter" and they form a negative feedback cycle that strongly suppresses the production of power at the truncation scale of the model.

Following Lander and Hoskins (1997), the physics filter employs the Hoskins filter (Hoskins, 1980; Sardeshmukh and Hoskins, 1984) to perform the spatial smoothing. This has the form:

$S_{n}=\exp -\left(\frac{n(n+1)}{n_{o}\left(n_{o}+1\right)}\right)^{p}$,

where $n$ is the total wavenumber, $n_{o}$ is a transition wavenumber, and $0 \leq S_{n} \leq 1$ is the real factor multiplying the complex spectral coefficients of the field to be filtered. Here we take $p=2$ and derive $n_{o}$ such that $S_{n}=0.1$ at the truncation wavenumber $n=N$. This results in values of $n_{o}=38$ and 51 for spectral resolutions of T47 and T63 respectively.

The physics filter is not typically run in DYN-MAM. It is applied primarily during CCM-MAM integrations. When it is employed, the physics filter is taken to act on all prognostic spectral fields entering the physics package. The main impact of the physics filter is a significant reduction in the amount of mass correction associated with hole filling. The main prognostic variables show a relatively weaker sensitivity to the presence of the filter.

\subsection{DYN-MAM configuration}

CMAM typically employs horizontal resolutions of T47 and T63 (T31 for chemical-climate modelling of long climatechange simulations). The model lid is located at $5 \times 10^{-4} \mathrm{hPa}$ (approximately $100 \mathrm{~km}$ ). In this configuration 71 vertical levels are employed. Figure 1 illustrates the vertical resolution as a function of height in both AGCM (solid line) and CMAM (dotted line). Identical resolution is used in the two models from the surface up to roughly $5 \mathrm{~km}$ elevation. Above this level CMAM employs higher resolution which smoothly

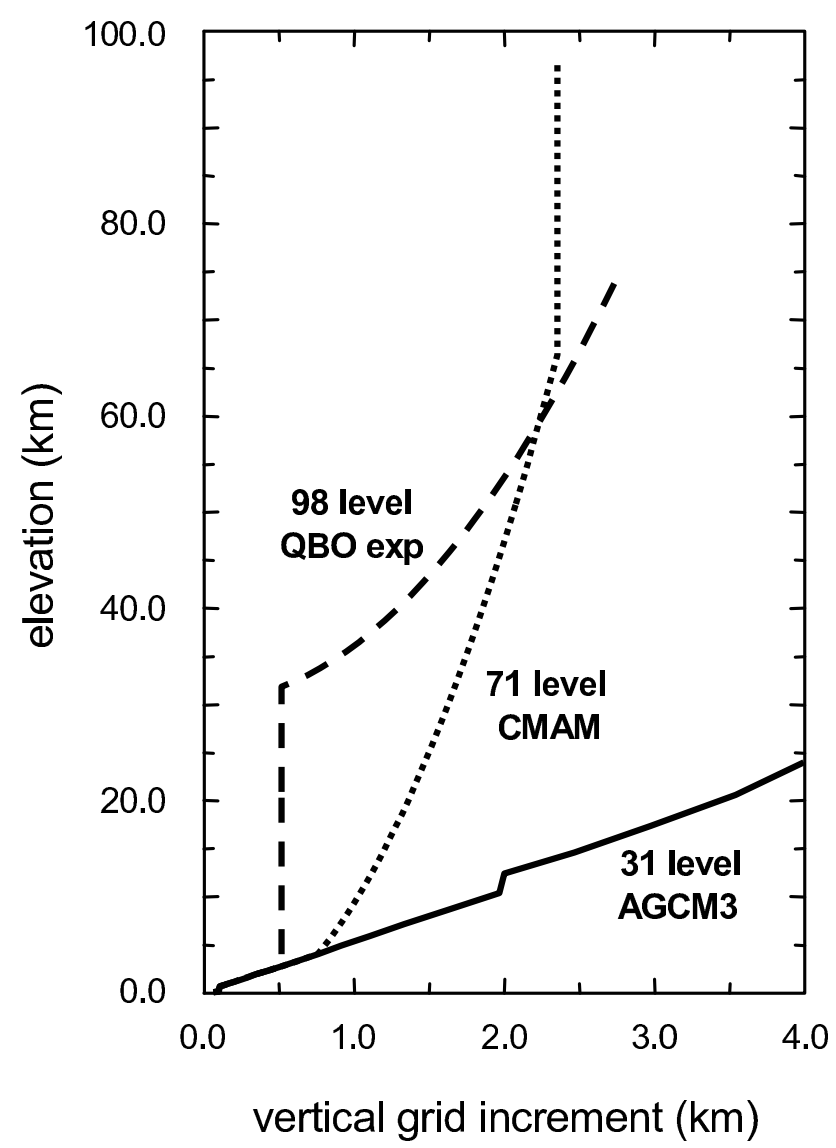

Fig. 1. Model vertical resolution as a function of height for AGCM3 (31 levels, solid line), CMAM (71 levels, dotted line), and a high resolution stratospheric QBO experiment (98 levels, dashed line). A $7 \mathrm{~km}$ scale-height is assumed in the conversion from pressure to height. The highest levels in AGCM3 approach a resolution of $8 \mathrm{~km}$ and are not displayed on this figure.

decreases to vertical increments of approximately $2.5 \mathrm{~km}$. Earlier versions of the CMAM (e.g. Beagley et al., 1997) employed a similar model lid elevation but only 50 vertical levels resulting in degraded resolution everywhere in the vertical.

Unless otherwise stated the discussion and analysis will focus on present-day climate simulations of five years duration. These simulations employ repeated annual cycle forcings of ozone, sea ice, and sea-surface temperature. Such simulations will be referred to simply as "present-day" climate runs.

In tropospheric mode AGCM3 employs the SUNYA ozone data set (Wang et al., 1995) for present-day climate experiments. These data are imported into the model as a series of 12 monthly mean, zonal mean, fields and are interpolated down to the time step of the model. The SUNYA data set only reaches to $1 \mathrm{hPa}$ and so DYN-MAM uses the middle atmosphere data set of Kita and Sumi (1986). While this older 
data set extends up to $100 \mathrm{~km}$, it is important to note that the vertical resolution is coarser than the SUNYA data and it pertains to an earlier, "pre-ozone-hole" period.

Boundary conditions for sea-surface temperature (SST) and sea ice concentration (SIC) in both tropospheric AGCM3 and CMAM are derived from the AMIPII boundary condition data set spanning the 17 year period 1979-1996 (Taylor et al., 2001). Present-day simulations employ a repeated annual cycle of monthly mean fields of the SST and SIC averaged over this 17 -year period linearly interpolated down to the time-step of the model.

\subsection{Impact of orographic drag}

Scinocca and McFarlane (2000, hereafter SM00) have identified the tropospheric impact of moving from the previous McFarlane (1987, hereafter M87) gravity wave-drag (GWD) scheme to the new scheme discussed in Sect. 2.6. In that analysis, parameters for the new scheme were determined by attempting to obtain minimal biases for both zonal wind and mean sea-level pressure. SM00 demonstrate a global RMS bias reduction of roughly $20-25 \%$ for both of these quantities in moving to the new scheme.

The stratospheric impact of moving to the new GWD scheme is considered here. This is investigated initially by two 5-year present-day climate runs of DYN-MAM - one employing the M87 scheme, the other employing the SM00 scheme. To simplify the comparison, all non-orographic GWD has been turned off in these runs.

In Fig. 2 we present the zonal mean, seasonal mean DJF and JJA zonal winds for the SPARC Reference Climatology (SPARC 2002) and from the M87 and SM00 simulations. Comparing the middle atmospheric response to each of these schemes we see that some of the largest differences are located in the core of the wintertime jet in the southern hemisphere (SH). The use of M87 results in zonal winds that are approximately $40 \mathrm{~ms}^{-1}$ stronger in the wintertime SH mesospheric jet core than when SM00 is used (panel d vs $\mathrm{f}$ ). In fact, the SM00 zonal winds in this location are close to the observed SPARC reference climatology (panel b) and the CIRA winds (Fleming et al., 1990). The magnitude of the winds in northern hemisphere $(\mathrm{NH})$ winter also roughly match observations in both runs (panels $\mathrm{c}$ and $\mathrm{e}$ ).

Obvious problems with these two simulations occur in the summertime mesosphere. The peak Easterly winds in the jet core are in excess of $40 \mathrm{~ms}^{-1}$ of the observations. Absent in both of these runs is the summertime mesopause wind reversal near $85 \mathrm{~km}$ elevation (or $5 \times 10^{-3} \mathrm{hPa}$ ). These two biases are well known and associated with the absence of non-orographic GWD in these runs.

In Fig. 3 we present the zonal-mean zonal wind from three additional runs in which the non-orographic scheme of Scinocca (2003, hereafter S03) is introduced into the model. The parameter settings employed for the non-orographic scheme in all the runs are identical and equivalent to those derived in S03. The three simulations are defined by different settings of the SM00 ororgraphic scheme. The first simulation (panels $\mathrm{c}$ and d) corresponds to the default settings of SM00 employed for tropospheric modelling in AGCM3 (this simulation will be labelled SM00_TROP). This configuration of SM00 is identical to that represented in panels (e) and (f) of Fig. 2. The simulation itself is essentially equivalent to that reported by $\mathrm{S} 03$ (see Fig. $8 \mathrm{e}$ and $\mathrm{f}$ of $\mathrm{S} 03$ ).

A comparison of the winds from the SM00_TROP simulation with the SPARC climatology (panels a and b of Fig. 2) reveals significant improvement. The winds in the jet cores have roughly the correct location and magnitude. The summertime mesopause wind reversal is now present and also reasonably represented. Further analysis and discussion of the DYN-MAM response to this configuration of the model may be found in S03 and Scinocca (2002).

The SM00_TROP simulation was the starting point for the CHM-MAM configuration of the model recently employed for the 2006 WMO/UNEP Scientific Assessment of Ozone Depletion. While the general pattern of the winds seems reasonable in this configuration, there occur temperature biases in the model that are unacceptable for polar ozone studies. This is highlighted in panels (a) and (b) of Fig. 4 where the zonal-mean temperature bias relative to the SPARC climatology is presented as a function of latitude and height up to $2 \mathrm{hPa}$. In the SH wintertime polar stratosphere (panel b) there occurs a significant warm bias extending from roughly 200 to $7 \mathrm{hPa}$. Such climatological temperatures are in excess of the threshold values necessary for the formation of polar stratospheric clouds (PSCs) and so problematic for modelling the heterogeneous chemical reactions that drive polar ozone loss.

To correct for this temperature bias modifications were made to the SM00 scheme. These modifications followed from several unpublished studies where experiments had been undertaken for the similar purpose of alleviating the warm bias in the SH wintertime polar stratosphere (Stuart Webster and Byron Boville, 2003, personal communication). The modifications are comprised of two changes. The first is a reduction of the total amount of momentum launched by the scheme. Typically, this involves altering the value of a basic scaling parameter in the orographic scheme. In the SM00 scheme this parameter is the integrated radial dependence of the pressure drag $G(v)$ (i.e. Eq. 6.6 of Phillips, 1984).

The second modification is less conventional and it involves an adjustment to the criterion employed to determine the onset of wave breaking. In the SM00 and M87 schemes a critical inverse Froude number $F r_{\text {crit }}$ is employed as a threshold value on the local inverse Froude number $F r$ of the wave field (i.e. the wave's non-dimensional amplitude at any elevation). Locally, when $F r>F r_{\text {crit }}$ momentum is transferred from the wave field to the flow in the manner outlined in M87. Both the SM00 and M87 schemes employ a value $F r_{\text {crit }}=(0.5)^{1 / 2}$. 

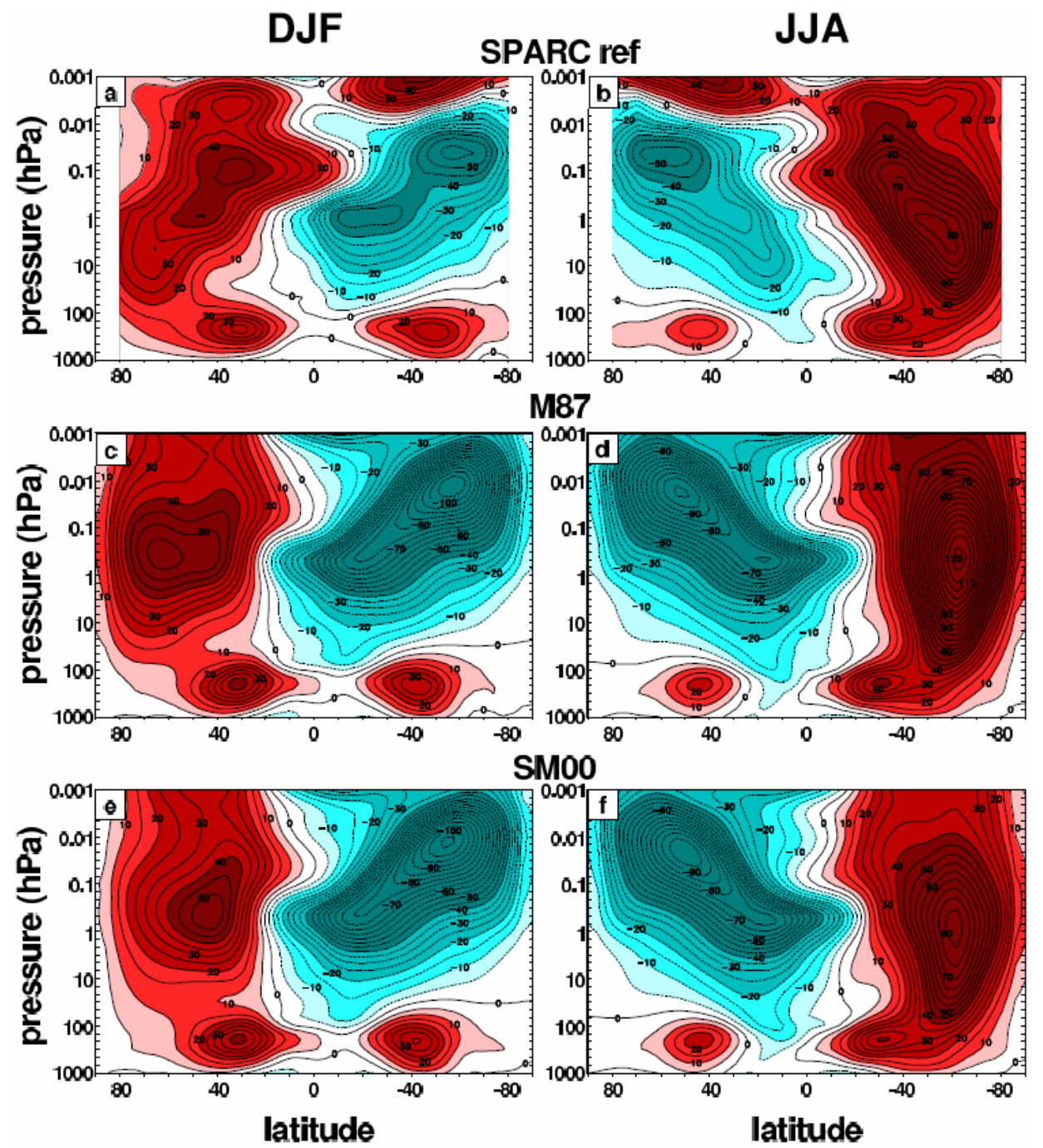

Fig. 2. Zonal-mean seasonal-mean zonal winds for the SPARC reference climatology (panels a and b), and from DYN-MAM simulations employing only the orographic gravity-wave drag parameterization of McFarlane (1987) (panels c and d), and Scinocca and McFarlane (2000) (panels e and f).

For the 2006 WMO ozone assessment then we employ $F r_{\text {crit }}=0.375$ and reduce $G(v)$ from a value of 1 down to 0.65 . We shall refer to this configuration as SM00_WMO. The zonal-mean temperature anomaly for the SM00_WMO configuration is presented in panels (c) and (d) of Fig. 4. It is clear that these two changes to the SM00 scheme almost exclusively target the polar warm bias leaving the remainder of the model response unaltered. However, from the zonalmean zonal-wind field for the SM00_WMO configuration (Fig. 3) we can see that this adjustment has come at the expense of an enhancement of the SH wintertime mesospheric jet (panel d), which exceeds the observed jet by $30 \mathrm{~ms}^{-1}$. Further, there is an increase in the mean sea-level pressure bias in the SM00_WMO configuration which is consistent with the trade-off between wind and mean sea-level pressure biases discussed in SM00.
While it was necessary to accept these biases for the purpose of modelling polar ozone, it is not clear whether the adjustment to $F r_{\text {crit }}$ was required. The reduction of $F r_{\text {crit }}$ to a value of 0.375 is very low and arguably unphysical. In a third experiment, SM00_MOD, it is demonstrated that the same targeted response may be obtained by an adjustment of $G(v)=0.25$ alone. We shall refer to this configuration as SM00_MOD. The zonal-mean zonal wind and temperature are respectively presented for the SM00_MOD simulation in panels (e) and (f) of Figs. 3 and 4. The SM00_WMO and SM00_MOD runs bear a striking similarity to one another indicating that a similar model response may be obtained by an adjustment to $G(v)$ alone. Because of the reduced momentum flux in SM00_MOD relative to SM00_WMO, however, the tropospheric mean sea-level pressure bias is slightly larger in magnitude. 

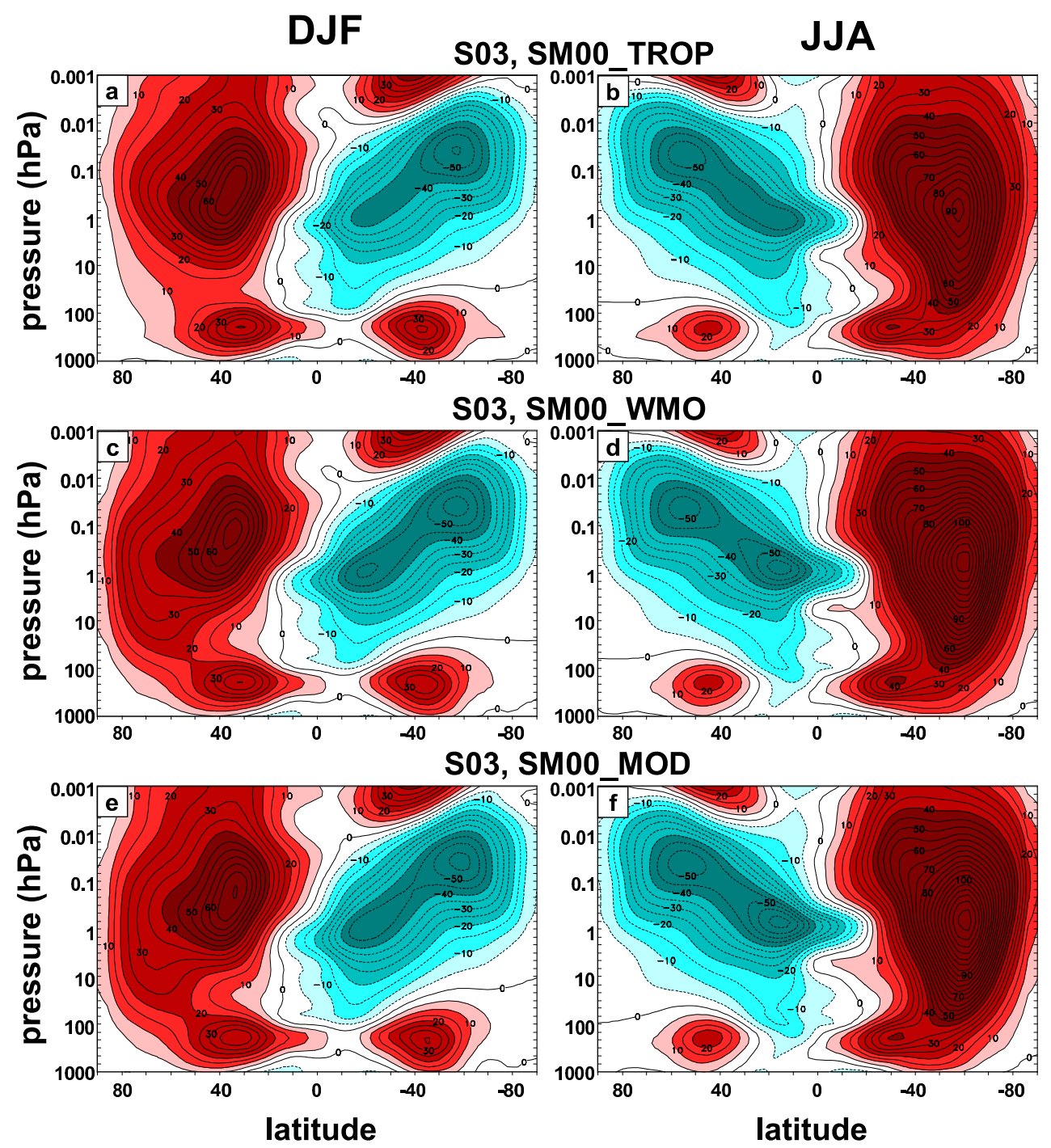

Fig. 3. Zonal-mean seasonal-mean zonal winds for three simulations employing the Scinocca (2003, S03) non-orographic gravity wave parameterization in addition to the Scinocca and McFarlane (2000) orographic scheme. Each of the three simulations employs different parameter settings for the orographic scheme: (panels a and b) SM00_TROP employs the settings described in Scinocca and McFarlane (2000) $\left(G(v)=1.0\right.$ and $\left.F r_{\text {crit }}=(0.5)^{1 / 2}\right)$ (see text), (panels $\mathbf{c}$ and d) SM00_WMO employs the settings for the CMAM contribution to the 2006 WMO ozone assessment $\left(G(v)=0.65\right.$ and $\left.F r_{\text {crit }}=0.375\right)$, and (panels e and $\mathbf{f}$ SM00_MOD employs the settings $G(v)=0.25$ and $F r_{\text {crit }}=(0.5)^{1 / 2}$. The close similarity of SM00_WMO and SM00_MOD indicates that the adjustment to $F r_{\text {crit }}$ is not required.

In alleviating the lower stratospheric temperature biases near $50 \mathrm{hPa}$ we have focused on adjustments to the orographic rather than non-orographic GWD. This is because the winds and temperatures in this region are more sensitive to the orographic drag in AGCM3. This may in part be due to the decision to launch the non-orographic waves from $100 \mathrm{hPa}$ (S03) in DYN-MAM. Model's that launch their non-orographic gravity waves from the surface, or in the troposphere, may find that these waves have more influence on the winds and temperatures near $50 \mathrm{hPa}$.

\subsection{Seasonal cycle of SH polar vortex}

Chemical climate model simulations of the recent past presented in Eyring et al. (2006; hereafter E06) identified a common bias in the timing of the breakdown of the SH wintertime polar vortex (i.e. E06, Fig. 2). Relative to three reanalysis data sets, the breakdown was delayed by a period that ranged from several days to more than a month. This was referred to as a "cold pole" problem in the models. Given that the models generally produced a realistic amount of planetary wave flux from the troposphere to stratosphere, as deduced by comparisons of eddy heat flux near the tropopause 

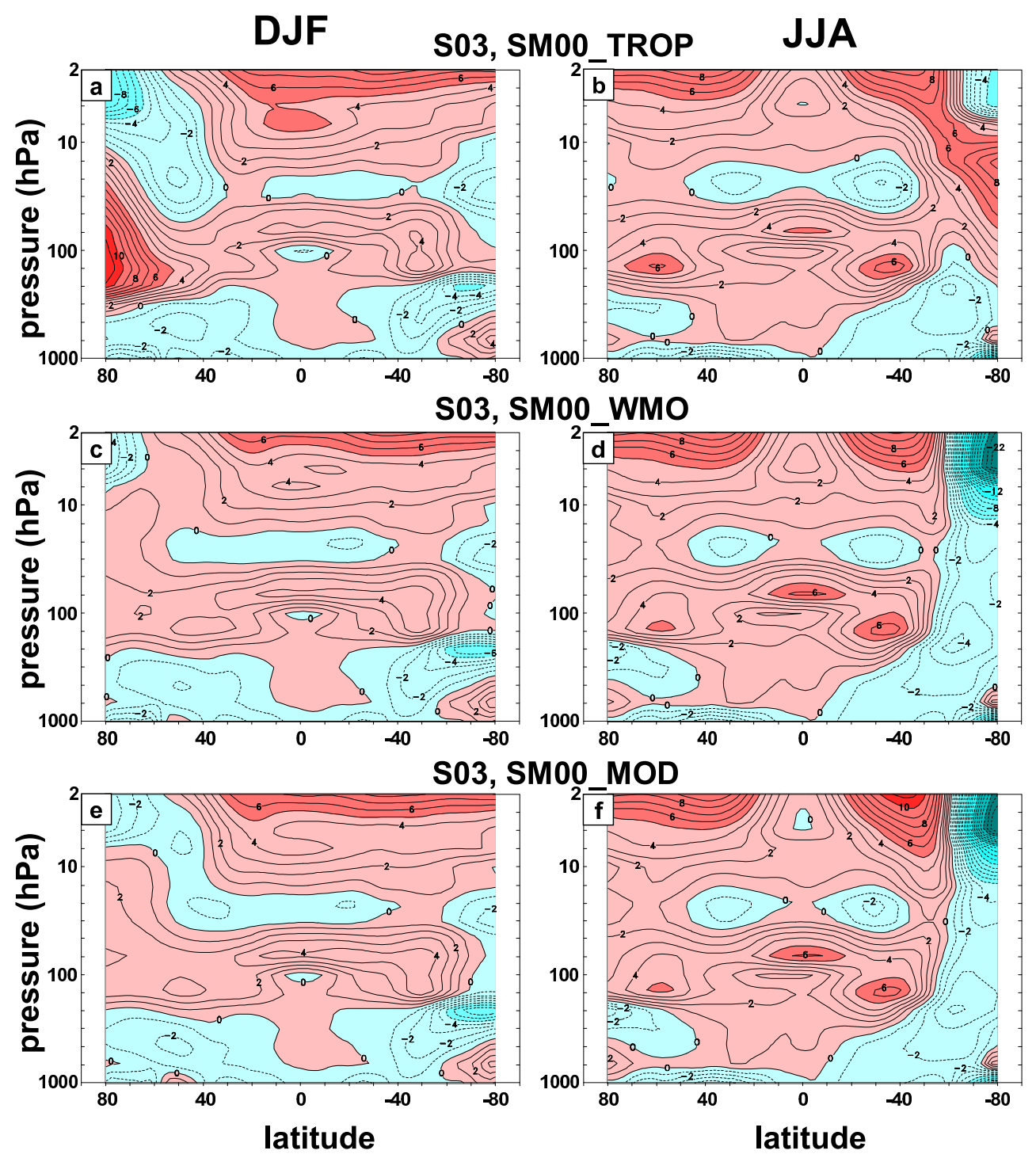

Fig. 4. As in Fig. 3 but displaying the zonal-mean temperature bias relative to the SPARC reference climatology.

with reanalysis data, it was thought that this bias was associated with a weakness in the representation of the stratosphere itself. One possibility is that the initial state of the polar vortex leading into Spring is too strong (cold) in the models and therefore more difficult to break down. In this section we briefly consider this explanation for the late breakdown of the polar vortex in the CMAM.

An excessively strong $\mathrm{SH}$ wintertime polar vortex in CMAM seems like a plausible explanation for its late breakdown given the tuning exercise of the DYN-MAM described in the previous section, which resulted in the configuration SM00_WMO. As already noted, the colder temperatures in SM00_WMO produced a SH polar vortex of excessive strength at all elevations (Fig. 3d). The configuration of SM00_TROP arrived at by Scinocca (2003) had a more representative $\mathrm{SH}$ wintertime polar vortex (Fig. 3b).
To investigate this potential explanation, we consider the timing of the breakdown of the SH wintertime polar vortex for various configurations of CMAM. In Fig. 5 we present the time evolution of the zero line of the zonal-mean wind at $60^{\circ} \mathrm{S}$ based on the climatological mean annual cycle calculated from daily data. The observed evolution is represented in Fig. 5 by UKMO reanalysis data (Swinbank and O'Neill, 1994) (black). The evolution of the CCM-MAM (REF1) contribution to E06 for pre-ozone hole (1971-1975) and peak ozone-hole conditions (1990-1999) is represented by the red and blue curves, respectively. The blue curve corresponds directly to the CMAM result presented in E06 (Fig. 2).

Comparing the blue and red curves in Fig. 5 it is clear that the spring ozone loss has resulted in a delay in the breakdown of the polar vortex by a few weeks. Such a delay is consistent with the expected radiative response to springtime ozone 


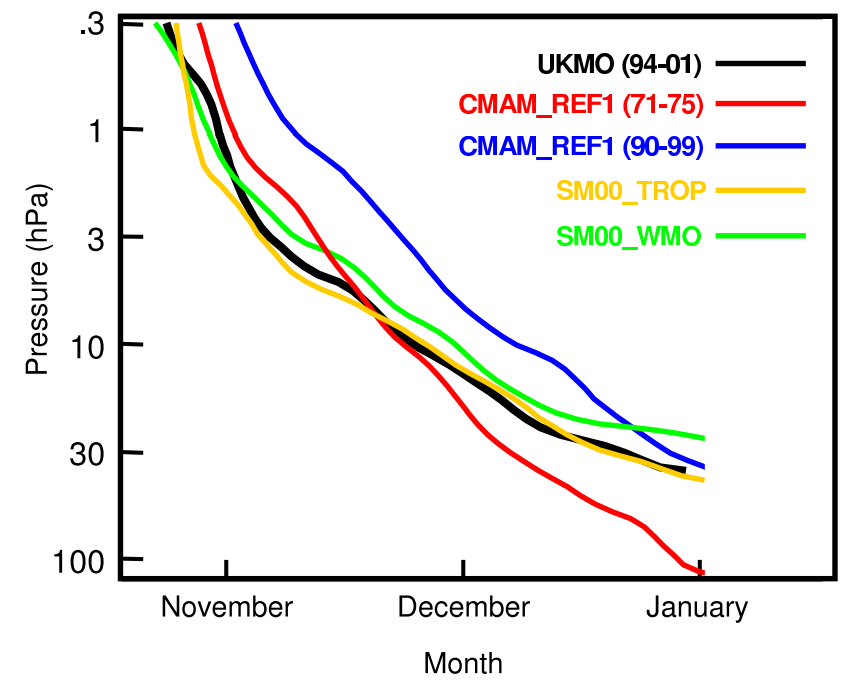

Fig. 5. Time evolution of the zero line of the zonal-mean wind at $60^{\circ} \mathrm{S}$ based on the climatological mean annual cycle. The observed evolution as represented by UKMO reanalysis data (Swinbank and O’Neill, 1994) is shown in black.

loss (Shindell and Schmidt, 2004). However, as noted earlier, the breakdown is now delayed by a few weeks relative to the observations. In the absence of springtime ozone loss, the zero-wind line of the CCM_MAM (red) and the DYN-MAM base model SM00_WMO (green) should descend earlier than the observed zero-wind line. They both actually closely follow the timing of the observed break down. This all seems consistent with the notion that the excessive strength of the wintertime polar vortex in the SM00_WMO configuration is the reason for its longevity into Spring. If this were the reason it would also follow that the SM00_TROP configuration (yellow) should show a significantly earlier breakdown than the observations given its weaker (warm) wintertime polar vortex. This, however, is not the case. While the breakdown of the polar vortex in SM00_TROP is slightly earlier than SM00_WMO, it also closely matches observations.

From Fig. 4b it is clear that SM00_TROP did not have a wintertime cold-pole problem. In fact, the SM00_TROP configuration possessed a significant warm bias at $60^{\circ} \mathrm{S}$ at elevations above $100 \mathrm{hPa}$. The results of Fig. 5 are even more surprising given that the prescribed ozone field used for SM00_TROP and SM00_WMO was the older data set of Kita and Sumi (1986), which does not include Springtime ozone loss. This would all seem to indicate that the delay in the springtime breakdown of the SH polar vortex in the CMAM does not stem from an excessively strong (cold) wintertime polar vortex leading into spring. The late springtime breakdown bias seems effectively independent of the strength of the wintertime polar vortex.

\subsection{Modelling of a spontaneous QBO}

The studies of Takahashi $(1996,1999)$ and Horinouchi and Yoden (1998) have established the importance of resolved gravity waves in the driving of a spontaneous QBO in climate models. These studies demonstrate that the role of resolved waves is determined by two factors - sufficiently high vertical resolution in the lower stratosphere (roughly $0.5 \mathrm{~km}$ ), and a parameterization of deep convection with enough temporal variability to force a significant spectrum of resolved gravity waves.

Since climate models employ a variety of deep convective parameterizations, there occur large inter-model differences in the amounts of resolved gravity waves in the tropics (Horinouchi et al., 2003). This means that a spontaneous QBO in any two models can result from significantly different combinations of resolved and parameterized gravity waves. A detailed study of the the properties of resolved waves in AGCM3, and their relationship to tropical convection, can be found in Scinocca and McFarlane (2004).

Since the background of resolved gravity waves is essentially a property of each GCM, the main quantity available to tune a spontaneous QBO is the parameterized nonorographic gravity waves in the tropics. This tuning usually takes the form of an enhancement of the momentum flux launched in the tropics relative to the extratropics. Such an enhancement is often justified (e.g. McLandress 2000) by the greater convective activity in the tropics. Here we consider the modelling of a spontaneous QBO in the CMAM based on these ideas.

In Fig. 6 we present time-height evolution of zonal-mean zonal wind at the equator for two sets of $5 \mathrm{y}$ present-day simulations based on the SM00_WMO configuration of DYNMAM. The left column employs the usual 71-level CMAM version, while the right column employs a 98-level version with $0.5 \mathrm{~km}$ resolution in the lower stratosphere (see Fig. 1). From top to bottom, these simulations employ a launch flux of parameterized non-orographic gravity waves that is everywhere uniform (panels a and b), enhanced at tropical latitudes by a factor of two (panels $\mathrm{c}$ and d), and by a factor of 4 (panels e and f). The enhancement is specified as zonallysymmetric and time invariant. Its latitudinal dependence is taken to be that of the normalized annual-mean zonal-mean convective precipitation in the tropics. (Similar results are obtained with an idealized Gaussian profile with a latitudinal half-width of $15^{\circ}$.)

The SM00_WMO configuration (panel a) displays a slight downward propagation of easterlies extending from the semiannual oscillation (SAO) at $1 \mathrm{hPa}$ down to roughly $20 \mathrm{hPa}-$ approaching an annual period at that level. Enhancing the vertical resolution (panel b) appears to allow all easterlies from the SAO to descend down to $20 \mathrm{hPa}$ resulting in perpetual easterlies near $10 \mathrm{hPa}$. Neither of these simulations display a tendency towards producing a spontaneous QBO. Enhancing the tropical non-orographic gravity-wave flux by 

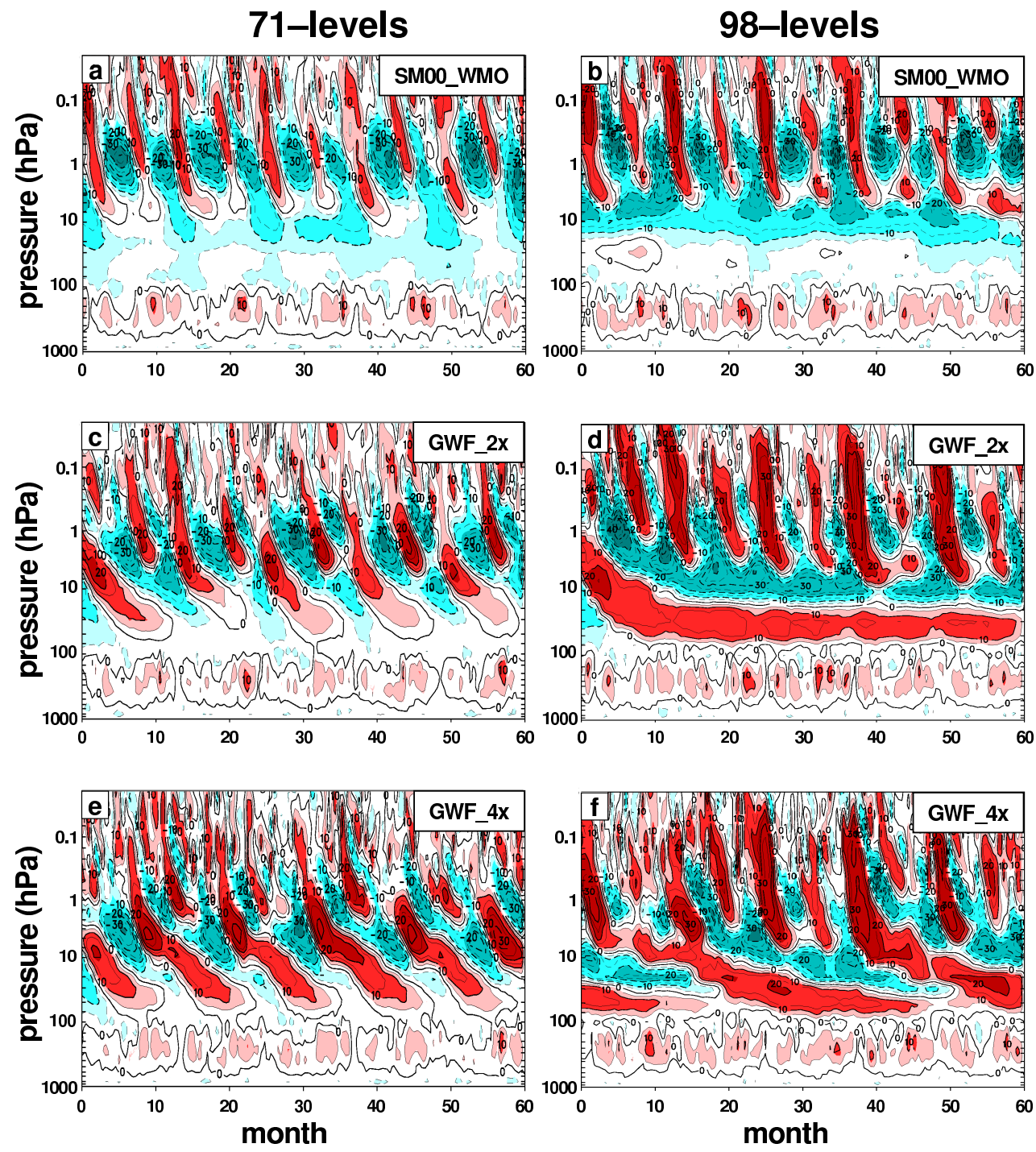

Fig. 6. Time-height evolution of zonal-mean zonal wind at the equator for two sets of $5 \mathrm{y}$ present-day simulations based on the SM00_WMO configuration of DYN-MAM. Simulations employing the standard 71-level version of CMAM are on the left while simulations employing a 98-level version of the model with enhanced vertical resolution in the stratosphere are on the right. From top to bottom, the flux of nonorographic gravity waves is constant at all latitudes (panels $\mathbf{a}$ and $\mathbf{b}$ ), increased in the tropics by a factor of 2 (panels $\mathbf{c}$ and $\mathbf{d}$ ), and by a factor of 4 (panels e and $\mathbf{f}$ ).

a factor of two and then a factor of four (panels c and e) in the standard 71-level version of the model causes the production of descending shear zones of alternating westerlies and easterlies. The period, however appears locked to the annual cycle. Repeating the tropical enhancement at higher vertical resolution results in dramatically different behaviour. At an enhancement of twice the flux, the westerlies descend and are locked near $50 \mathrm{hPa}$ implying an infinite period for the oscillation.

Simple models of the QBO (Baldwin, 2001) suggest that an increase/decrease in momentum flux should decrease/increase the period of the QBO. This behaviour is revealed when the flux is increased from $2 \times$ to $4 \times$ for the case of high stratospheric resolution (panel $d$ and $\mathrm{f}$ ). There occurs a decrease from an infinite period down to approximately $2 \mathrm{y}$. This behaviour is not recovered, however, at low stratospheric resolution. In decreasing the launch flux from $4 \times$ to $2 \times$ (panel e and c) there is no influence on the period of the oscillation. It seems to affect only the depth over which the shear layers descend. The inability of the launch flux to affect the period when low stratospheric vertical resolution is employed was identified earlier by McLandress (2000). A more detailed anlysis of sensitivy of the observed QBO to parameterized and resolved waves is provided by Giorgetta et al. (2006). 


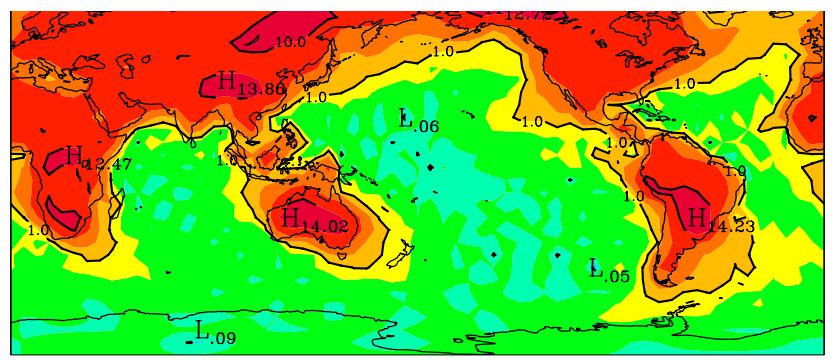

(B) Hybrid advection

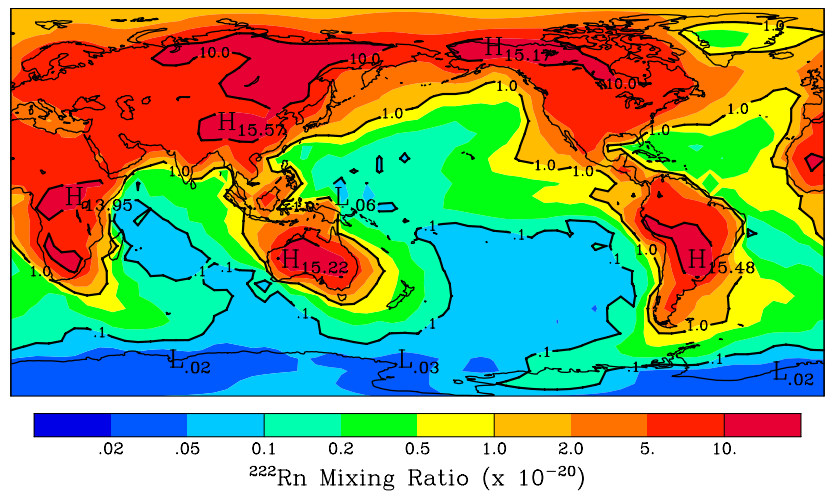

Fig. 7. June average ratio of radon-222 concentration in the lowest model layer (approximately $100 \mathrm{~m}$ thick) is displayed for spectral advection of the mixing ratio (panel a) and spectral advection of the hybridized mixing ratio (panel $\mathbf{b}$ ).

The QBO simulation displayed in Fig. 6f has been extended and its impact on the variability of the stratospheric polar vortex is currently being analyzed. At this time, no further work has been invested to fine-tune the QBO in CMAM. Obvious tests would include progressively degrading the vertical resolution in the lower stratosphere to determine the minimum resolution that will support a QBO. Another would be to adjust the launch height to improve its structure and fine tune the tropical enhancement of momentum flux to improve its period, which is too long at 35 months. These and other sensitivity tests will be conducted in the near future.

\section{Summary}

In this paper we have documented the basic properties of the Canadian Centre for Climate Modelling and Analysis (CCCma) third-generation atmospheric climate model AGCM3. A more in depth description of the model physics may be found in McFarlane et al. (2005) along with a detailed comparison of the model response relative to the secondgeneration model AGCM2.

AGCM3 continues to be used as the underlying model for middle-atmosphere dynamical- and chemical-climate modelling, seasonal forecasting, and CCCma's first generation Earth system model CanESM1. Here we have focused on the upward extension of AGCM3 into the stratosphere and mesosphere. This version of the model is referred to as the Canadian Middle-Atmosphere Model (CMAM) and we have focused the discussion primarily on the dynamical version DYN-MAM.

Here we have considered the impact of the new (Scinocca and McFarlane, 2000) and old (McFarlane, 1987) orographic gravity-wave drag schemes on the middle atmosphere. It was found that significantly more momentum flux reaches the wintertime stratosphere and mesosphere with the new scheme. The strength of the wintertime mesospheric jet is no longer over-estimated with the new scheme and there is generally a closer correspondence with observations.

The ability of the CMAM to produce a spontaneous QBO was also investigated. Sensitivity experiments were undertaken in which the vertical resolution in the region 100$10 \mathrm{hPa}$ was increased to $0.5 \mathrm{~km}$ from the standard CMAM value of $1-2 \mathrm{~km}$. The higher resolution allowed resolved waves to more fully participate in the driving of any modelled QBO (Takahashi, 1996, 1999; Horinouchi and Yoden, 1998). Following the approach of others, the remaining tuning came in the form of an enhancement of the launch momentum flux of parameterized nonorographic gravity waves in the tropics. Two sets of simulations were undertaken for several strengths of tropical flux enhancement - one with the increased vertical resolution and the other with standard vertical resolution. It was found that only the increased vertical resolution configuration produced a reasonable looking QBO whose period displayed the expected sensitivity to the gravity-wave source flux. The period of QBO-like features in simulations with the standard CMAM resolution were locked to annual cycle and did not display the expected sensitivity to the source flux. The properties of the CMAM QBO and its impact on extratropical variability is currently under investigation and will be published in a separate study.

The source of the systematic bias identified in Eyring et al. (2006), in which the modelled breakdown of the SH wintertime polar vortex occurs too late in Spring, was investigated in the dynamical version of CMAM. Here we considered the possibility that the initial state of the polar vortex leading into Spring is too strong (cold) in the models and therefore more difficult to break down. This seemed plausible given that the SH wintertime polar vortex in CMAM was tuned to be strong (cold) to ensure the formation of polar stratospheric clouds for modelling polar ozone. However, such sensitivity to the initial state of the polar vortex was not found in CMAM. Simulations with a weak (warm) wintertime polar vortex and with a specified ozone that did not include an ozone hole, did not produce the expected early breakdown relative to present observations. In CMAM at least, the delayed breakdown is relatively insensitive to the strength of the polar vortex leading into Spring.

While AGCM3 is continuing to be used for middle atmosphere modelling, it will soon be supplanted by a new fourth-generation version of the CCCma climate model. Improvements include a new correlated-K-distribution radiation 
scheme (Li, 2002; Li and Barker, 2002, 2005), parameterization of shallow convection (von Salzen and McFarlane, 2002), prognostic clouds with a full micro-physics package (based on Lohmann and Roeckner, 1996), and a bulk sulphur cycle (based on Lohmann et al., 1999). A developmental version of AGCM4 employing these improvements has been presented by von Salzen et al. (2005) and participated in the recent cloud performance assessment of Williams and Webb (2008).

\section{Appendix A}

To illustrate the utility of the hybridized variable, results from tests with radon-222 as a tracer variable are presented in Fig. 7. Radon-222 is emitted from soils and is removed from the atmosphere by radioactive decay with a half-life of 3.8 days. Given the physical characteristics of radon222 , with emissions largely only over land and a short atmospheric lifetime, the concentration in surface air displays large gradients between continental and maritime locations. Accordingly, radon-222 has been widely used to study the properties of atmospheric transport schemes in models (e.g. Jacob et al., 1997; Considine et al., 2005). For the tests presented here, radon-222 was assumed to be emitted from unfrozen ground at a constant rate of 1.0 atoms cm $\mathrm{cm}^{-2} \mathrm{~s}^{-1}$ with emission from snow-covered ground reduced by $70 \%$. No emission of radon was given for land covered by permanent ice (glaciers), while a small emission rate of 0.005 atoms $\mathrm{cm}^{-2} \mathrm{~s}^{-1}$ was specified over oceans.

In Fig. 7 the June average mixing ratio of radon-222 concentration (volume mixing ratio) in the lowest model layer (approximately $100 \mathrm{~m}$ thick) is displayed for spectral advection of the mixing ratio without hybridization (panel a) and with hybridization (panel $b$ ). The case with hybridization employed values of $p=2$ and $q_{o}=2.0 \times 10^{-19}$ and $3.5 \times 10^{-20}$ respectively for radon and lead in Eq. (3). In both cases, gradients are highly localized near continental boundaries and relatively low values are found over oceans and ice-covered land. In panel (a) however these regions of relatively low concentration feature prominent Gibbs ripples and few values smaller than $0.2 \times 10^{-20}$. A comparison (not shown here) with available radon-222 measurements at remote marine locations such as Crozet and Kerguelen Islands in the subAntarctic Indian Ocean (Balkanski and Jacob, 1990) indicates that the simulated concentrations in panel (a) are much too large at these locations.

By contrast, with hybridization (panel b), the concentration field over oceans and ice-covered land is much smoother, and features large regions having concentrations lower than $0.1 \times 10^{-20}$, including values as low as $0.02 \times 10^{-20}$ over Antarctica, an order of magnitude lower than in panel (a). Such a distribution is more physically plausible and is more in line with available observations, whereas without hybridization the tracer field is several times too large in remote locations.
Acknowledgements. The authors thanks B. Merryfield, and K. Von Salzen for their careful reading of the manuscript and helpful comments.

Edited by: V. Fomichev

\section{References}

Abdella, K. and McFarlane, N. A.: Parameterization of the surfacelayer exchange coefficients for atmospheric models, Bound.-Lay. Meteorol., 80, 223-248, 1996.

Arakawa, A. and Schubert, W. H.: Interaction of a cumulus cloud ensemble with the large scale environment. Part I., J. Atmos. Sci., 31, 674-701, 1974.

Austin, J., Shindell, D., Beagley, S. R., Bruhl, C., Dameris, M., Manzini, E., Nagashima, T., Newman, P., Pawson, S., Pitari, G., Rozanov, E., Schnadt, C., and Shepherd, T. G.: Uncertainties and assessments of chemistry-climate models of the stratosphere, Atmos. Chem. Phys., 3, 1-27, 2003, http://www.atmos-chem-phys.net/3/1/2003/.

Baker, G. A.: Essentials of Padé Approximants. New York, Academic Press, 306 pp., 1975.

Baldwin, M. P., Gray, L. J., Dunkerton, T. J., Hamilton, K., Haynes, P. H., Randel, W. J., Holton, J. R., Alexander, M. J., Hirota, I., Horinouchi, T., Jones, D. B. A., Kinnersley, J. S., Marquardt, C., Sato, K., and Takahashi, M.: The Quasi-Biennial Oscillation, Rev. Geophys., 39, 179-229, 2001.

Balkanski, Y. J. and Jaco, D. J.: Transport of continental air to the subantarctic Indian Ocean, Tellus, 42B, 62-75, 1990.

Beagley, S. R., de Grandpré, J., Koshyk, J. N., McFarlane, N. A., and Shepherd, T. G.: Radiative-dynamical climatology of the first-generation Canadian middle atmosphere model, Atmos. Ocean, 35, 293-331, 1997.

Beljaars, A. C. M. and Holtslag, A. A. M.: Flux parameterization over land surface for atmospheric models, J. Appl. Meteorol., 30, 327-341, 1991.

Boer, G. J.: A hybrid moisture variable suitable for spectral GCMs, Research Activities in Atmospheric and Oceanic Modelling, Report No. 21, WMO/TD-No. 665, World Meteorological Organization, Geneva, 1995.

Clough, S. A., Kneizys, F. X., and Davies, R. W.: Line shape and the water vapor continuum, Atmos. Res., 23, 229-241, 1989.

Cosby, B. J., Hornberger, G. M., Clapp, R. B., and Ginn, T. R.: A statistical exploration of the relationships of soil moisture characteristics to the physical properties of soils, Water Resour. Res., 20, 682-690, 1984.

Considine, D. B., Bergmann, D. J., and Liu, H.: Sensitivity of Global Modeling Initiative chemistry and transport model simulations of radon-222 and lead-210 to input meteorological data, Atmos. Chem. Phys., 5, 3389-3406, 2005, http://www.atmos-chem-phys.net/5/3389/2005/.

Daley, R., Girard, C., Henderson, J., and Simmonds, I.: Short-term forecasting with a multi-level spectral primitive equation model, Atmosphere, 14, 98-116, 1976.

deGrandpré, J., Beagley, S. R., Fomichev, V. I., Griffioen, E., McConnell, J. C., Medvedev, A. S., and Shepherd, T. G.: Ozone climatology using interactive chemistry: Results from the Canadian Middle Atmosphere Model, J. Geophys. Res., 105, 26475 $26491,2000$. 
Evans, W. F. J., Puckrin, E., Li, J., and Lavoie, H.: Comparison of clear-sky surface radiative fluxes simulated with radiative transfer models, Can. J. Remote Sens., 30, 903-912, 2004.

Eyring, V., Butchart, N., Waugh, D. W., Akiyoshi, H., Austin, J., Bekki, S., Bodeker, G. E., Boville, B. A., Brühl, C., Chipperfield, M. P., Cordero, E., Dameris, M., Deushi, M., Fioletov, V. E., Frith, S. M., Garcia, R. R., Gettelman, A., Giorgetta, M. A., Grewe, V., Jourdain, L., Kinnison, D. E., Mancini, E., Manzini, E., Marchand, M., Marsh, D. R., Nagashima, T., Newman, P. A., Nielsen, J. E., Pawson, S., Pitari, G., Plummer, D. A., Rozanov, E., Schraner, M., Shepherd, T. G., Shibata, K., Stolarski, R. S., Struthers, H., Tian, W., and Yoshiki, M.: Assessment of temperature, trace species and ozone in chemistry-climate model simulations of the recent past, J. Geophys. Res., 111, D22308, doi:10.1029/2006JD007327, 2006.

Eyring, V., Waugh, D. W., Bodeker, G. E., Cordero, E., Akiyoshi, H., Austin, J., Beagley, S. R., Boville, B. A., Braesicke, P., Brühl, C., Butchart, N., Chipperfield, M. P., Dameris, M., Deckert, R., Deushi, M., Frith, S. M., Garcia, R. R., Gettelman, A., Giorgetta, M. A., Kinnison, D. E., Mancini, E., Manzini, E., Marsh, D. R., Matthes, S., Nagashima, T., Newman, P. A., Nielsen, J. E., Pawson, S., Pitari, G., Plummer, D. A., Rozanov, E., Schraner, M., Scinocca, J. F., Semeniuk, K., Shepherd, T. G., Shibata, K., Steil, B., Stolarski, R. S., Tian, W., and Yoshiki, M.: Multi-Model Projections of Stratospheric Ozone in the 21st Century, J. Geophys. Res., 112, D16303, doi:10.1029/2006JD008332, 2007.

Fleming, E. L., Chandra, S., Barnett, J. J., and Corney, M.: Zonal mean temperature, pressure, zonal wind and geopotential height as functions of latitude, Adv. Space Res., 10, 11-59, 1990.

Fomichev, V. I., Kutepov, A. A., and Shved, G. M.: Parameterization of $15 \mu \mathrm{m} \mathrm{CO}_{2}$ band cooling in the middle atmosphere (15115) km, J. Atmos. Terr. Phys., 47, 1037-1049, 1993.

Fomichev, V. I. and Blanchet, J.-P.: Development of the new CCC/GCM longwave radiation model for extension into the middle atmosphere, Atmos. Ocean, 33, 513-529, 1995.

Fomichev, V. I. and Blanchet, J.-P., and Turner, D. S.: Matrix parameterization of the $15 \mu \mathrm{m} \mathrm{CO}_{2}$ band cooling in the middle and upper atmosphere for, variable $\mathrm{CO}_{2}$ concentration, J. Geophys. Res., 103, 11 505-11 528, 1998.

Fomichev, V. I., Fu, C., de Grandpre, J., Beagley, S. R., Ogibalov, V. P., and McConnell, J. C.: Model thermal response to minor radiative energy sources and sinks in the middle atmosphere, J. Geophys. Res., 109, D19107, doi:10.1029/2004JD004892, 2004.

Fomichev, V. I., Ogibalov, V. P., and Beagley, S. R.: Solar heating by the near-IR $\mathrm{CO}_{2}$ bands in the mesosphere, Geophys. Res. Lett., 31, L21102, doi:10.1029/2004GL020324, 2004.

Fouquart, Y. and Bonnel, B.: 1980: Computations of solar heating of the Earth's atmosphere: A new parameterization, Beitr. Phys. Atmos., 53, 35-62, 2007.

Giorgetta, M. A., Manzini, E., Roeckner, E., Esch, M., and Bengtsson, L.: Climatology and forcing of the quasi-biennial oscillation in the MAECHAM5 model, J. Climate, 19, 3882-3901, 2006.

Hines, C. O.: Doppler-spread parameterization of gravity-wave momentum deposition in the middle atmosphere. Part I: Basic formulation, J. Atmos. Sol.-Terr. Phy., 59, 371-386, 1997a.

Holzer, M.: Optimal spectral topography and its effect on model climate, J. Climate, 9, 2443-2463, 1996.

Horinouchi, T. and Yoden, S.: Wave-mean flow interaction associated with a QBO-like oscillation simulated in a simplified GCM,
J. Atmos. Sci., 55, 502-526, 1998.

Horinouchi, T., Pawson, S., Shibata, K., Langematz, U., Manzini, E., Giorgetta, M. A., Sassi, F., Wilson, R. J., Hamilton, K., de Granpre, J., and Scaife, A. A.: Tropical cumulus convection and upward propagating waves in middle atmospheric GCMs, J. Atmos. Sci., 60, 2765-2782, 2003.

Hoskins, B. J.: Representation of the earth topography using spherical harmonics, Mon. Weather Rev., 108, 111-115, 1980.

Jacob, D. J., Prather, M. J., Rasch, P. J., Shia, R.-L., Balkanski, Y. J., Beagley, S. R., Bergmann, D. J., Blackshear, W. T., Brown, M., Chiba, M., Chipperfield, M. P., de Grandpré, J., Dignon, J. E., Feichter, J., Genthon, C., Grose, W. L., Kasibhatla, P. S., Köhler, I., Kritz, M. A., Law, K., Penner, J. E., Ramonet, M., Reeves, C. E., Rotman, D. A., Stockwell, D. Z., VanVelthoven, P. F. J., Verver, G., Wild, O., Yang, H., and Zimmerman, P.: Evaluation and intercomparison of global atmospheric transport models using 222Rn and other short-lived tracers, J. Geophys. Res., 102, 5953-5970, 1997.

Jonsson, A., de Grandpré, J. and McConnell, J. C.: A comparison of mesospheric temperatures from the Canadian Middle Atmosphere Model and HALOE observations: zonal mean and signature of the solar diurnal tide, Geophys. Res. Lett., 29(9), 1346, doi:10.1029/2001GL014476, 2002.

Kita, K. and Sumi, A.: Reference ozone models for middle atmosphere, University of Tokyo Geophysical Institute, available from Division of Meteorology, Geophysical Institute, University of Tokyo, Bunkyo, Tokyo, Japan, 113, 26 pp., 1986.

Koshyk, J. N., Boville, B. A., Hamilton, K., Manzini, E., and Shibata, K.: The kinetic energy spectrum of horizontal motions in middle atmosphere models, J. Geophys. Res., 104, 27177 27 190, 1999.

Lander, J. and Hoskins, B. J.: Believable scales and parameterizations in a spectral transform model, Mon. Weather Rev., 125, 292-303, 1997.

Li, J.: Accounting for Unresolved Clouds in a 1D Infrared Radiative Transfer Model. Part I: Solution for Radiative Transfer, Including Cloud Scattering and Overlap, J. Atmos. Sci., 59, 3302-3320, 2002.

Li, J. and Barker, H. W.: Accounting for Unresolved Clouds in a 1D Infrared Radiative Transfer Model. Part II: Horizontal Variability of Cloud Water Path, J. Atmos. Sci., 59, 3321-3339, 2002.

Li, J. and Barker, H. W.: A radiation algorithm with correlated kdistribution. Part I: local thermal equilibrium, J. Atmos. Sci., 62, 286-309, 2005.

Lohmann, U., von Salzen, K., McFarlane, N., Leighton, H. G., and Feichter, J.: Tropospheric sulphur cycle in the Canadian general circulation model, J. Geophys. Res., 104, 26 833-26 858, 1999.

Lohmann, U. and Roeckner, E.: Design and performance of a new cloud microphysics scheme developed for the ECHAM general circulation model, Climate Dyn., 12, 557-572, 1996.

Lord, S. J.: Interactions of a cumulus cloud ensemble with the largescale environment, Part III: Semi-prognostic test of the ArakawaSchubert cumulus parameterization, J. Atmos. Sci., 39, 104-113, 1982.

Manzini, E. and McFarlane, N. A.: The effect of varying the source spectrum of a gravity-wave drag parameterization in a general circulation model, J. Geophys. Res., 103, 31 523-31 539, 1998.

McFarlane, N. A.: The effect of orographically excited gravitywave drag on the circulation of the lower stratosphere and tro- 
posphere, J. Atmos. Sci., 44, 1175-1800, 1987.

McFarlane, N. A., Boer, G. J., Blanchet, J. P., and Lazare, M.: The Canadian Climate Centre second-generation general circulation model and its equilibrium climate, J. Climate, 5, 1013-1044, 1992.

McFarlane, N. A., Scinocca, J. F., Lazare, M., Harvey, R., Verseghy, D., and Li, J.: The CCCma third generation atmospheric general circulation model, CCCma Internal Rep., available online at http: //www.cccma.ec.gc.ca/models/gcm3.shtml, 25 pp., 2005.

McLandress, C.: Seasonal variability of the diurnal tide: Results from the Canadian Middle Atmosphere General Circulation Model, J. Geophys. Res., 102, 29747-29764, 1997.

McLandress, C.: Sensitivity studies using the Hines and Fritts gravity-wave drag parameterizations, in: Gravity Wave Processes and their Parameterization in Global Climate Models, edited by: Hamilton, K., Springer-Verlag, 245-256, 1997.

McLandress, C.: Equatorial oscillations in a middle atmosphere general circulation model, SPARC 2000 General Assembly, Mar del Plata, Argentina, 6-10 November, 1-6.10, 2000.

McLandress, C. and Scinocca, J. F.: The GCM Response to Current Parameterizations of Non-Orographic Gravity-Wave Drag, J. Atmos. Sci., 62, 2394-2413, 2005.

McLandress, C. and Ward, W. E.: Modulation of gravity wave drag in the mesosphere and lower thermosphere by tides and the effects on the time mean flow - model results, AGU Geophysical Monograph, 87 (The Upper Mesosphere and Lower Thermosphere: A Review of Experiment and Theory), 145-152, 1995.

Medvedev, A. S. and Klaassen, G. P.: Vertical evolution of gravity wave spectra and the parameterization of associated wave drag, J. Geophys. Res., 100, 25 841-25 853, 1995.

Mein, R. G. and Larson, C. L.: Modelling Infiltration During Steady Rain, Water Resour. Res., 9, 384-394, 1973.

Merryfield, W. J., McFarlane, N., and Lazare, M.: A generalized hybrid transformation for tracer advection, Research Activities in Atmospheric and Oceanic Modelling, Report No. 33, WMO/TDNo. 1161a, 2003.

Monin, A. S. and Obukhov, A. M.: Basic laws of turbulent mixing in the atmosphere near the ground, Izvestiya Akademii Nauk SSR Fizika Atmosfery i Okeana, 24, 163-187, 1954.

Moorthi, S. and Suarez, M. J.: Relaxed Arakawa-Schubert, A Parameterization of Moist Convection for General Circulation Models, Mon. Weather Rev., 120, 978-1002, 1992.

Morcrette, J. J.: Description of the radiation Scheme in the ECMWF model, Technical Memorandom vol. 165, European Centre for Medium Range Weather Forecasts, p. 26, 1989.

Ogibalov, V. P. and Fomichev, V. I.: Parameterization of solar heating by the near IR $\mathrm{CO}_{2}$ bands in the mesosphere, Adv. Space Res., 32(5), 759-764, 2003.

Ölafsson, H. and Bougeault, P.: Nonlinear flow past an elliptic mountain ridge, J. Atmos. Sci., 53, 2465-2489, 1996.

Orszag, S.: Transform Method for the Calculation of VectorCoupled Sums: Application to the Spectral Form of the Vorticity Equation, J. Atmos. Sci., 27, 890-895, 1970.

Plummer, D. A., Caya, D., Frigon, A., Cote, H., Giguere, M., Paquin, D., Biner, S., Harvey, R., and de Elia, R.: Climate and Climate Change over North America as Simulated by the Canadian RCM, J. Climate, 19, 3112-3132, 2006.

Polavarapu, S. M., Ren, S., Rochon, Y., Sankey, D., Ek, N., Koshyk, J., and Tarasick, D.: Data assimilation with the Canadian Middle
Atmosphere Model, Atmos. Ocean, 43, 77-100, 2005.

Phillips, D. S.: Analytical surface pressure and drag for linear hydrostatic flow over three-dimensional elliptical mountains, J. Atmos. Sci., 41, 1073-1084, 1984.

Priestley, A.: A quasi-conservative version of the semi-Lagrangian advection scheme, Mon. Weather Rev., 121, 621-629, 1993.

Roberts, R. E., Selby, J. E. A., and Biberman, L. M.: Ifrared continuum absorption by atmospheric water in the 8-12 micron window, Appl. Opt., 15, 2085-2090, 1976.

Sardeshmukh, P. D. and Hoskins, B. J.: Spatial smoothing on the sphere, Mon. Weather Rev., 112, 2524-2529, 1984.

Scinocca, J. F.: The effect of back-reflection in the parametrization of non-orographic gravity-wave drag, J. Meteorol. Soc. Jpn., 80, 939-962, 2002.

Scinocca, J. F.: An Accurate Spectral Non-Orographic Gravity Wave Parameterization for General Circulation Models, J. Atmos. Sci., 60, 667-682, 2003.

Scinocca, J. F. and McFarlane, N. A.: The parameterization of drag induced by stratified flow over anisotropic orography, Q. J. Roy. Meteor. Soc., 126, 2353-2393, 2000.

Scinocca, J. F. and McFarlane, N. A.: The Variability of Modelled Tropical Precipitation, J. Atmos. Sci., 61, 1993-2015, 2004.

Shettle, E. P. and Fenn, R. W.: Models for the aerosols of the lower atmosphere and the effects of humidity variations on their optical properties, Environmental Research Papers, No. 676, AFGL-TR79-0214, USAF, 94 pp., 1979.

Shindell, D. T. and Schmidt, G. A.: Southern Hemisphere climate response to ozone changes and greenhouse gas increases, Geophys. Res. Lett., 31, L18209, doi:10.1029/2004GL0020724, 2004.

SPARC: SPARC Intercomparison of Middle Atmosphere Climatologies, SPARC Report No. 3, edited by: Randel, W., Chanin, M.-L., and Michaut, C., 96 pp., 2002.

Slingo, A.: A GCM parameterization for the shortwave radiative properties of water clouds, J. Atmos. Sci., 46, 1419-1427, 1989.

Stewart, J. B.: Modelling surface conductance of pine forest, Agr. Forest Meteorol., 43, 19-35, 1988.

Swinbank, R. and O'Neill, A.: A stratosphere-troposphere data assimilation system, Mon. Weather Rev., 122, 686-702, 1994.

Takahashi, M.: Simulation of the stratospheric quasi-biennial oscillation using a general circulation model, Geophys. Res. Lett., 23, 661-664, 1996.

Takahashi, M.: Simulation of the quasi-biennial oscillation in a general circulation model, Geophys. Res. Lett., 26, 1307-1310, 1999.

Taylor, K. E., Williamson, D., and Zwiers, F.: Amip II sea surface temperature and sea ice concentration boundary conditions, 23 June 1997 (revised 6 April 2001), http://www-pcmdi.llnl.gov/ amip/AMIP2EXPDSN/BCS/amip2bcs.html, 2001.

Verseghy, D. L.: CLASS-A Canadian land surface scheme for GCMS. 1. Soil Model, Int. J. Climatol., 11, 111-133, 1991.

Verseghy, D. L.: The Canadian Land Surface Scheme (CLASS): Its history and future, Atmos. Ocean, 38, 1-13, 2000.

Verseghy, D. L., McFarlane, N. A., and Lazare, M.: A Canadian Land Surface Scheme for GCMs:II, Vegetation model and coupled runs, Int. J. Climatol., 13, 347-370, 1993.

von Salzen, K. and McFarlane, N. A.: Parameterization of the bulk effects of lateral and cloud-top entrainment in transient shallow cumulus clouds, J. Atmos. Sci., 59, 1405-1429, 2002. 
von Salzen, K., McFarlane, N. A., and M. Lazare: The role of shallow convection in the water and energy cycles of the atmosphere, Clim. Dynam., 25, 671-688, 2005.

Webb, T., Bartlein, P. J., Harrison, S. P., and Anderson, K. H.: Vegetation, lake levels, and climate in eastern North America for the past 18000 years, in: Global Climates since the Last Glacial Maximum, edited by: Wright Jr., H. E, Kutzbach, J. E., Webb III, T., Ruddiman, W. F., Street-Perrot, F. A., and Bartlein, P. J., University of Minnesota Press, Minneapolis, MN, USA, 415-467, 1993.

Wang, W.-C., Liang, X.-Z., Dudek, M. P., Pollard, D., and Thompson, S. L. : Atmospheric ozone as a climate gas, Atmos. Res., 37, 247-256, 1995.

Warner, C. D. and McIntyre, M. E.: On the propagation and dissipation of gravity wave spectra through a realistic middle atmosphere, J. Atmos. Sci., 53, 3213-3235, 1996.
Williams, K. D. and Webb, M. J.: A quantitative climate performance assessment of cloud regimes in GCMs, Clim. Dynam., in press, 2008.

Wilson, M. F. and Henderson-Sellers, A.: A global archive of land cover and soils data for use in general-circulation climate models, J. Climate, 5, 119-143, 1985.

World Meteorological Organization/United Nations Environment Programme (WMO/UNEP): Scientific Assessment of Ozone Depletion: 2006, Rep. 50, World Meteorol. Org., Global Ozone Res. and Monit. Proj., Geneva, Switzerland, 2007.

Zhang, G. J. and McFarlane, N. A.: Sensitivity of climate simulations to the parameterization of cumulus convection in the CCCGCM, Atmos. Ocean, 3, 407-446, 1995.

Zhong, W. Y. and Haigh, J. D.: Improved broad-band emissivity parameterization for water-vapor cooling rate calculations, J. Atmos. Sci., 52, 124-138, 1995. 